CIUDAD Y TERRITORIO

ESTUDIOS TERRITORIALES

ISSN(P): 1133-4762; ISSN(E): 2659-3254

Vol. LIII, № 207, primavera 2021

Págs. 23-46

https://doi.org/10.37230/CyTET.2021.207.02

\title{
Infraestructura verde y ordenación del territorio en España
}

\author{
Berezi EloRrieta-SAnZ ${ }^{(1)}$ \\ Jorge Olcina-Cantos ${ }^{(2)}$
}

(1) Universidad de Barcelona. (2) Universidad de Alicante.

RESUMEN: La ordenación del territorio cuenta desde hace unos años con una herramienta de planificación sostenible: la infraestructura verde, que se ha ido incorporando en normas y planes territoriales de varios países occidentales. Entre ellos se incluye España, donde recientemente se ha publicado un borrador de estrategia estatal de infraestructura verde. El presente trabajo analiza la incorporación de la infraestructura verde a las políticas territoriales de las comunidades autónomas españolas mediante dos vías: la aprobación de estrategias específicas y su integración en los planes de ordenación territorial. Así, se identifican y analizan en profundidad aquellas comunidades autónomas que pueden considerarse ejemplo de buenas prácticas: Comunidad Valenciana, País Vasco y Cantabria, cuyos planes territoriales confieren a la infraestructura verde un papel importante en la definición, delimitación y gestión de los usos del suelo.

PALABRAS CLAVE: Ordenación del territorio; Infraestructura verde; Comunidades autónomas; Planificación sostenible.

\section{Green Infrastructure and Spatial Planning in Spain.}

ABSTRACT: Spatial planning uses in last years a sustainable planning tool: green infrastructure, which has been incorporated into territorial regulations and plans in several western countries. These include Spain, where an official document for the development of a green infrastructure strategy has recently been published by the central government. This paper analyses the integration of green infrastructure into the territorial policies of the Spanish autonomous communities through two different procedures: the approval of specific strategies and its integration into the spatial planning plans. We analyse in depth those autonomous communities that can be considered examples of good practices: Valencian Community, Basque Country and Cantabria, whose territorial plans give green infrastructure an important role in the definition, delimitation and management of land uses.

KEYWORDS: Spatial Planning; Green infrastructure; Autonomous Communities; Sustainable territorial management.

Recibido: 31.01.2020; Revisado: 09.06.2020

Correo electrónico: berezielorrieta@gmail.com; No ORCID: https://orcid.org/0000-0002-7473-2314;

Correo electrónoco: jorge.olcina@ua.es; No ORCID: https://orcid.org/0000-0002-4846-8126

Los autores agradecen los comentarios y sugerencias realizados por los evaluadores anónimos, que han contribuido a mejorar y enriquecer el manuscrito original. 


\section{Introducción y objetivos}

a ordenación del territorio ha ido mejorando sus procedimientos y métodos de trabajo en las últimas décadas, en relación con la aparición de normas que han priorizado la consideración de los elementos naturales y culturales del medio como piezas importantes a considerar en la planificación de nuevos usos (Lo Piccolo \& Todaro, 2013). Se ha pasado, en muchos países del mundo occidental, de concepciones básicamente económicas de la planificación territorial, que consideran el suelo como un espacio de posibilidades, de asignación directa de nuevos usos, a posiciones que valoran los recursos naturales y el patrimonio histórico-artístico como elementos básicos de los territorios. Actualmente, la planificación de los usos del suelo es una de las principales herramientas para su protección y para la conservación de la biodiversidad, especialmente en países que se encuentran en un periodo de intensificación de dichos usos, como es el caso de España (Foley \& al. 2005), por lo que es necesario implementar nuevas formas de planeamiento que tengan como objetivo la sostenibilidad del territorio (FARIÑA \& NAREDO, 2010).

Podemos destacar dos nuevos elementos que se han incorporado a la planificación normativa de los países europeos en las últimas décadas. Por un lado, el paisaje, que se ha ido convirtiendo en un instrumento operativo a la hora de establecer nuevos usos en el territorio. Los principios contenidos en el Convenio Europeo del Paisaje de $\mathbf{2 0 0 0}$ han sido integrados progresivamente en las normativas urbanísticas y del territorio de los países y regiones de la Unión Europea (JONES \& STENSEKE, 2011). Las unidades paisajísticas han pasado a ser un objeto de trabajo principal en los estudios de sostenibilidad ambiental. Por otro lado, la infraestructura verde territorial, como herramienta de trabajo de todo proceso de planificación. Se trata de un concepto que surge en la arquitectura del paisaje norteamericana de principios del siglo XX (de la mano de Law Olmstead), que recogerá ideas ambientalistas de los siglos XVIII y XIX (MeLL, 2008), y que se ha ido incorporando en las últimas tres décadas a la planificación territorial de diversas escalas, principalmente regional y local (BREUSTE \& al, 2015). Como conexión conceptual y aplicada entre ambos elementos, (WEBER \& al., 2006) describen la infraestructura verde como la presencia y distribución de características naturales en el paisaje que, además de favorecer los procesos ecológicos, contribuye también a la salud y el bienestar humanos. Los conceptos "naturales" de ecosistema y paisaje se combinan así con aspectos básicos en el funcionamiento humano de las sociedades (LAFORTEZZA \& al., 2013).
En cualquier caso no existe una definición universalmente aceptada de la expresión "infraestructura verde", debido a la variedad de finalidades en que ha derivado su manejo en planificación territorial (Agencia Europea del Medio Ambiente, AEMA, 2011). FERIA \& SANTIAGo (2017: 121) incluso se han referido a ella como "concepto-paraguas", ya que abarca múltiples componentes a diferentes escalas, desde los anillos verdes en la escala urbana hasta las redes regionales, nacionales o supranacionales para la conservación de los hábitats naturales. BENEDICT \& McMAHON (2002) definen la infraestructura verde como una red interconectada de espacios verdes que conserva los valores naturales y las funciones del ecosistema y proporciona beneficios asociados a las poblaciones humanas.

En la misma línea, más recientemente, la Comisión Europea (CE, 2014: 7) la ha definido como

"una red estratégicamente planificada de zonas naturales y seminaturales de alta calidad con otros elementos medioambientales, diseñada y gestionada para proporcionar un amplio abanico de servicios ecosistémicos y proteger la biodiversidad tanto de los asentamientos rurales como urbanos".

Esta definición recoge los tres rasgos esenciales de la infraestructura verde que resultan comunes a la mayoría de las definiciones (AEMA, 2011): en primer lugar, la búsqueda de un alto nivel de conectividad entre los espacios que la componen; en segundo lugar, su vocación multifuncional (con funciones no sólo ambientales, sino también sociales y productivas); y por último, la adopción de un enfoque estratégico para su planificación y gestión.

Como se desprende de su definición, la infraestructura verde no es sólo una red de espacios protegidos o de corredores ecológicos, se trata de un concepto que abarca mucho más territorio desde un prisma multiescalar, multifuncional y multisectorial (CALZADA, 2019). Así, aunque su principal misión es la conservación de la biodiversidad (función ecológica), tiene también funciones productivas y culturales, relacionadas con el desarrollo y la calidad de vida, de tal modo que su gestión se concibe desde una perspectiva sistémica. De hecho, la inversión en infraestructura verde puede comportar incluso beneficios económicos, pues su contribución a la mitigación de los efectos del cambio climático resulta más rentable que la adopción de soluciones tecnológicas (VALLADARES \& al., 2017). Los elementos que componen la infraestructura verde son diversos, específicos de cada territorio y muy dependientes de la escala (Fernández de GatTA, 2018), de forma que puede incluir desde grandes espacios naturales protegidos hasta áreas verdes 
urbanas. Esta estructura multiescalar obliga a que los diferentes niveles competenciales se articulen correctamente para una regulación coherente y coordinada.

Así las cosas, la infraestructura verde parece destinada a integrar la planificación espacial, ecológica y socioeconómica en diferentes escalas, y debe contar en los procesos de planificación como herramienta cartográfica principal, a partir de la cual se determinan los suelos a conservar y se ordenan los nuevos crecimientos urbanísticos o de infraestructuras y equipamientos.

Para integrar la infraestructura verde en las políticas territoriales, desde un punto de vista instrumental, pueden contemplarse dos opciones: por un lado, pueden desarrollarse instrumentos específicos de ordenación para la infraestructura verde; por otro lado, puede incorporarse la infraestructura verde en los planes de ordenación territorial. En la presente investigación se pretende analizar ambas modalidades de ordenación de la infraestructura verde en una selección de casos de estudio. Así pues, el objetivo de esta investigación es analizar la ordenación de la infraestructura verde en las comunidades autónomas españolas, ya sea mediante la aprobación de estrategias específicas o mediante la integración de la infraestructura verde en los instrumentos de planificación territorial regionales.

\section{Método de análisis}

La metodología empleada es una combinación de diferentes técnicas cualitativas. El estudio parte de una revisión bibliográfica sobre el propio concepto de infraestructura verde, su implantación en las políticas públicas de diferentes contextos territoriales y su integración en la ordenación del territorio. Para ello, se han empleado tanto fuentes de tipo académico como fuentes institucionales o provenientes de organizaciones especializadas. Por un lado, para el estudio del contexto europeo, han sido fundamentales los trabajos publicados desde la Agencia Europea del Medio Ambiente (AEMA) así como desde la propia Comisión Europea (CE). En el contexto español, a su vez, destaca la propia Estrategia Estatal de Infraestructura Verde y de la Conectividad y la Restauración Ecológicas como documento institucional, así como otras fuentes académicas como el estudio de Feria \& Santiago (2017) sobre la integración de la infraestructura verde en la planificación de algunas áreas metropolitanas españolas.

En segundo lugar, se ha procedido al análisis de contenido de diversos documentos normativos y de planificación de las comunidades autónomas. Siguiendo la secuenciación de tareas mencionada por BARDIN (2002), se ha partido de un preanálisis en el que se han identificado y seleccionado la legislación territorial y de paisaje y los planes territoriales y de infraestructura verde de las comunidades autónomas. A continuación, se ha procedido a la propia explotación del material, analizando la presencia de la infraestructura verde en los documentos; y por último, se ha realizado el tratamiento de resultados, presentando la información en forma de tablas para facilitar su comparación y la obtención de una fotografía general de la incorporación de la infraestructura verde en el marco legal e instrumental. Por un lado, se ha elaborado una tabla (FIG. 4) con la legislación de ordenación territorial y de paisaje de las comunidades autónomas, donde se detalla si las leyes mencionan o no la infraestructura verde en su articulado. Por otro lado, se ha diseñado otra tabla (FIG. 5) donde se recoge, para cada comunidad autónoma, la existencia o no de una estrategia específica de infraestructura verde, el instrumento de planificación territorial regional, y la incorporación de la infraestructura verde en el mismo, clasificando dicha incorporación como directa (cuando el plan incluye explícitamente la infraestructura verde en sus determinaciones), indirecta (no se menciona la infraestructura verde explícitamente, pero sí gran parte de sus componentes) o nula (no se menciona la infraestructura verde ni la mayoría de sus componentes).

Con los resultados de este análisis general por comunidades, se ha realizado una selección de casos de estudio que se han considerado de interés por sus avances en la incorporación de la infraestructura verde a los procesos y políticas de planificación territorial. Concretamente, se han seleccionado las tres comunidades autónomas que, en sus planes territoriales, han integrado de forma directa o explícita la ordenación de la infraestructura verde: la Comunidad Valenciana, la Comunidad Autónoma del País Vasco y Cantabria. Para estos casos de estudio, una revisión bibliográfica más profunda ha permitido caracterizar el marco regulador, instrumental y de gobernanza relacionado con la ordenación del territorio y la infraestructura verde.

Más allá de esta caracterización general, interesa conocer la incorporación pormenorizada de la infraestructura verde en los planes de las comunidades autónomas seleccionadas, y realizar un análisis comparado que permita identificar las tendencias actuales en cuanto a la concepción de la infraestructura verde en dichos planes. Para ello, en primer lugar, se ha puesto la atención en la identificación de los componentes de la infraestructura verde de los tres planes (FIG. 7), así como 
en la coherencia que guardan con la Estrategia estatal de infraestructura verde, empleando una lista de control (check-list) con los componentes recogidos en dicha Estrategia que serían susceptibles de ser incorporados en la ordenación del territorio de escala regional (FIG. 8). Es decir, se han excluido del análisis los elementos que la Agencia Europea de Medio Ambiente en su propuesta metodológica asocia a la escala urbana (AEMA, 2011). La lista de control permite una lectura tanto en vertical (incorporación de los componentes en cada comunidad autónoma) como horizontal (identificación de los componentes más o menos presentes en los planes), lo que nutre la interpretación y conclusiones finales. En segundo lugar, se ha puesto la atención sobre la adopción de un enfoque multiescalar en los planes, estudiando las funciones atribuidas a la infraestructura verde en cada escala territorial (FIG. 9).

En suma, la información extraída de un análisis de contenido más detallado de los instrumentos de planificación regional se ha volcado progresivamente en las FIGS. 7, 8 y 9, permitiendo comprender mejor cómo se regula la infraestructura verde en cada plan y facilitando el análisis comparado entre los tres casos de estudio.

\section{Infraestructura verde, herramienta de planificación territorial sostenible}

La difusión del concepto de infraestructura verde ha sido considerablemente rápida en el contexto internacional y particularmente en el europeo, donde, además de una larga trayectoria de políticas ambientales, existe una preocupación importante por las transformaciones recientes de los usos del suelo y la fragmentación del paisaje.

Con el fin de mejorar el estado de la infraestructura verde en las ciudades y regiones europeas, la Estrategia de Biodiversidad hasta 2020 (CE, 2011) ya incluyó este elemento en su objetivo 2 , que se refiere al mantenimiento y mejora de los servicios ecosistémicos y la restauración de ecosistemas degradados mediante la incorporación de infraestructura verde a la ordenación territorial, lo que contribuiría a hacer sostenible el crecimiento de la UE. Además, este documento preveía la elaboración de una estrategia específica de infraestructura verde, que finalmente se publicaría en 2013 bajo el título "Mejora del capital natural de Europa" (CE, 2013), y que seguía la línea abierta por los anteriores programas y estrategias ambientales, climáticas o de biodiversidad.
La estrategia europea tiene como objetivo crear un marco robusto para fomentar y facilitar proyectos de infraestructura verde mediante los instrumentos financieros, políticos y jurídicos existentes. Como resultado de este marco, la infraestructura verde es identificada específicamente como una de las prioridades de inversión en diferentes políticas y programas, como la política agraria, ambiental o de cohesión, de donde ha venido principalmente el acceso a la financiación (del Fondo Europeo de Desarrollo Regional y del Fondo de Cohesión). Paralelamente a la integración en las políticas sectoriales, la Unión también promueve la incorporación de la infraestructura verde en las actuaciones de las escalas inferiores, para que se desarrollen y apliquen marcos nacionales y regionales que promuevan la restauración y la infraestructura verde (CE, 2015: 7).

Así pues, la UE entiende la infraestructura verde como una herramienta estratégica en el marco de las políticas de cohesión territorial, conservación de la naturaleza y fomento de la sostenibilidad urbana (FERIA \& SANTIAGO, 2017), buscado su integración de forma transversal y considerando sistémicamente la infraestructura verde en los procesos de planificación y toma de decisiones (GoBIERNO DE ESPAÑA, 2019). En definitiva, cumpliendo con lo previsto en la estrategia de infraestructura verde, la UE no sólo ha realizado una reflexión conceptual, un diagnóstico de su estado y una apuesta por la inclusión de la infraestructura verde en la planificación desde una visión estratégica, sino que también le ha asignado instrumentos de financiación y recomendaciones de inversión específicas para los proyectos.

Este impulso proveniente de la esfera europea también se ha traducido en una considerable integración de la infraestructura verde en la planificación territorial de los Estados miembros (AEMA, 2011). Según los resultados del proyecto GRETA - Green infrastructure: Enhancing biodiversity and ecosystem services for territorial development, del observatorio ESPON (Observatorio en Red de la Ordenación del Territorio Europeo), los 32 estados miembros de ESPON incluyen la infraestructura verde en sus políticas públicas, más allá de las políticas propias dirigidas a la conservación de la biodiversidad, aunque solo 11 de ellos tienen políticas específicas de infraestructura verde a nivel nacional (GARCíA-BLANCO \& al., 2019), entre los que podemos citar a Francia, Alemania, Holanda o Austria, entre otros. A estos países se sumará España cuando se apruebe definitivamente el borrador de su estrategia estatal de infraestructura verde.

Las escalas regional y local en Europa también ofrecen buenos ejemplos de la incorporación de la herramienta de la infraestructura verde en la 


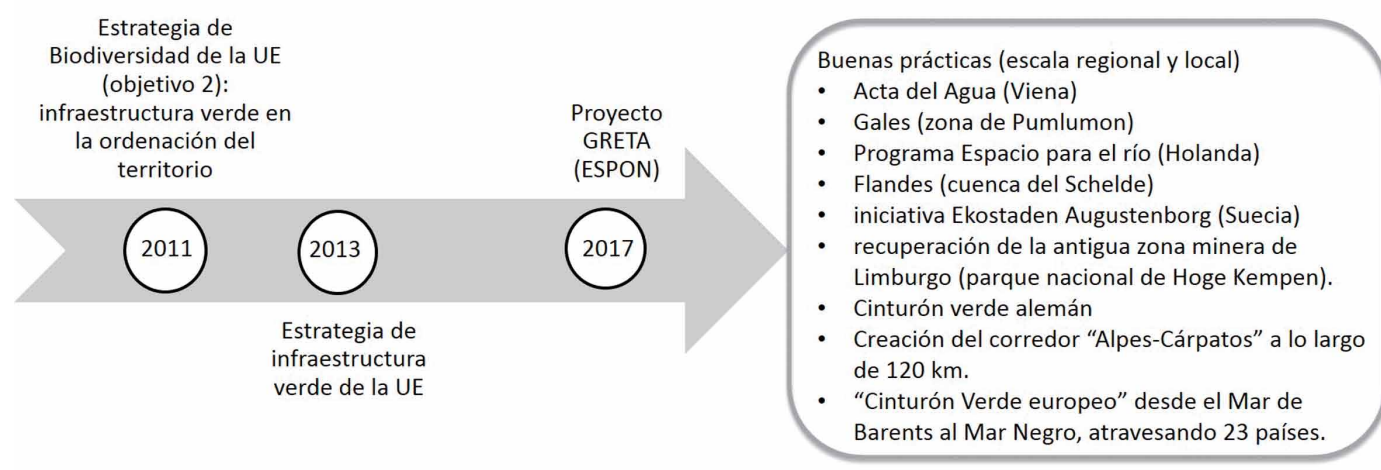

FIG. 1/ Principales hitos de la infraestructura verde en la Unión Europea.

Fuente: Elaboración propia.

planificación territorial (ver FIG. 1). Así, destacan las iniciativas desarrolladas en Gales (zona de Pumlumon), Flandes (cuenca del Schelde), la iniciativa Ekostaden Augustenborg (Suecia), o la recuperación de la antigua zona minera de Limburgo (parque nacional de Hoge Kempen), entre otras. Incluso se han llevado a cabo iniciativas supra-regionales y supra-estatales como la creación del corredor "Alpes-Cárpatos" a lo largo de 120 km., o del "Cinturón Verde europeo" desde el Mar de Barents al Mar Negro, atravesando 23 países.

En la escala local, hay dos aspectos concretos que recientemente han cobrado protagonismo como elementos de la infraestructura verde, en el marco del actual proceso de calentamiento climático: el desarrollo de sistemas de drenaje sostenible (verdeamiento de cursos fluviales urbanos; parques inundables; depósitos pluviales) y las acciones para la mejora del confort térmico que eviten los efectos del calor urbano, especialmente en verano (tejados verdes, fachadas verdes, manzanas verdes). De cara al futuro, los efectos del cambio climático se van a incorporar también como elementos de infraestructura verde tanto en la escala local como en la regional, a partir del empleo de modelos cada vez más ajustados (Vera-Rebollo \& al., 2019). Y en un doble sentido: por un lado, por el propio proceso de cambio climático y sus efectos en los elementos climáticos (cambios en las temperaturas y la precipitación); y por otro lado, por el incremento previsto de las manifestaciones atmosféricas extremas. De manera que se deberán incorporar a la infraestructura verde, de cara a la planificación territorial regional y local, efectos tales como las modificaciones en las áreas inundables o las sequías y su impacto en el abastecimiento urbano de agua, entre otros (ver FIG. 2).

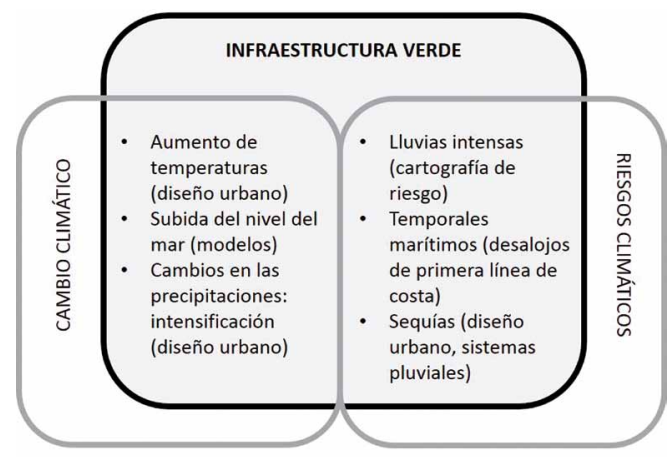

FIG. 2/ Aspectos del cambio climático y de los riesgos climáticos que pueden incorporarse a la infraestructura verde y la planificación territorial.

Fuente: Elaboración propia.

\section{La Estrategia Estatal de Infraestructura Verde y de la Conectividad y la Restauración Ecológicas}

El marco normativo referente a la protección de los sistemas naturales y los procesos ecológicos en España es amplio y complejo y las competencias se reparten entre las tres escalas principales: estatal, regional y local. En el campo de la infraestructura verde, los avances han sido significativos en los últimos años, aunque al ser un concepto relativamente reciente, la mayor parte de las normas básicas ambientales no la mencionan; sin embrago, sí citan otros conceptos que forman parte de la infraestructura verde (GoBIERNO DE EsPAÑA, 2019). 
El mayor referente normativo a nivel estatal para implementar estrategias de infraestructura verde viene dado por la ley española de Patrimonio Natural y Biodiversidad ${ }^{1}$, que pretende dar cumplimiento a las directrices provenientes de la UE e incorporar algunos de los objetivos de la estrategia europea sobre biodiversidad. Así, esta normativa fue la encargada de incorporar la infraestructura verde al ordenamiento jurídico español a partir de su reforma de 2015, y estableció la elaboración de una estrategia de infraestructura verde estatal para su diagnóstico y ordenación.

En mayo de 2019, el gobierno español publicó finalmente un borrador de Estrategia Estatal de Infraestructura Verde y de la Conectividad y la Restauración Ecológicas (ver FIG. 3), que derivó de las preliminares bases científico-técnicas, presentadas en 2017 y concebidas como el fundamento técnico y científico de la futura Estrategia estatal. El borrador de 2019 de la Estrategia fue asumido por un equipo amplio y multidisciplinar de expertos en diversas materias, aunque no estuvo exento de críticas por la escasa participación pública y transparencia en su elaboración. Aun así, la Estrategia deja de manifiesto la existencia de un interés político en impulsar la infraestructura verde desde el nivel estatal, dado que no existía hasta ese momento ningún instrumento de planificación en esta materia y escala.

El enfoque adoptado por esta Estrategia es el de la integración de los ecosistemas y sus servicios en la ordenación del territorio. No se presenta la infraestructura verde como una nueva figura de protección del patrimonio natural, sino como una herramienta integradora. A partir de la aprobación de la Estrategia, se supone que la normativa relacionada con las distintas intervenciones sobre el territorio debe integrar el concepto de infraestructura verde y las directrices emanadas de la Estrategia, lo que supone adoptar un nuevo modelo de planificación territorial.
La Estrategia estatal, como su propio nombre indica, adopta un enfoque estratégico cuya visión consiste en que, en 2050, existirá una red de infraestructura verde que permitirá asegurar el mantenimiento y mejora del capital natural garantizando soluciones naturales para los retos del bienestar humano, teniendo en cuenta el cambio climático. Para alcanzar las metas estratégicas, las diferentes administraciones son responsables de desplegar las actuaciones necesarias en cascada, desde las escalas superiores a las inferiores, con acciones adecuadas a cada nivel territorial, desde los corredores ecológicos regionales hasta los huertos urbanos.

La cuestión de la escala administrativa es un tema clave para implementar políticas de infraestructura verde, pues el propio concepto tiene un significado multiescalar. Por ello, el documento hace alusión explícita a la necesidad de un enfoque multiescalar así como de una buena coordinación interadministrativa, una cuestión clave si se tienen en cuenta los complejos problemas de gobernanza ambiental y territorial existentes (CE, 2019; FARINós \& ELORRIETA, 2017).

Una vez aprobada la Estrategia estatal, la ley de Patrimonio Natural y Biodiversidad establecía que las comunidades autónomas deberían desarrollar sus propias estrategias en un plazo máximo de tres años. La Estrategia estatal debe constituir una referencia para las estrategias regionales, siguiendo un proceso top-down en cascada, adaptando las orientaciones comunes a las realidades regionales. Sin embargo, como se observará en el siguiente apartado, ya hay algunas comunidades que se han avanzado a la publicación de la Estrategia estatal y han ido desarrollando sus propias iniciativas en los últimos años. Asimismo, existen ya algunos ejemplos en la escala local que han articulado instrumentos de planificación de la infraestructura verde, como Zaragoza, Vitoria-Gasteiz o Madrid.

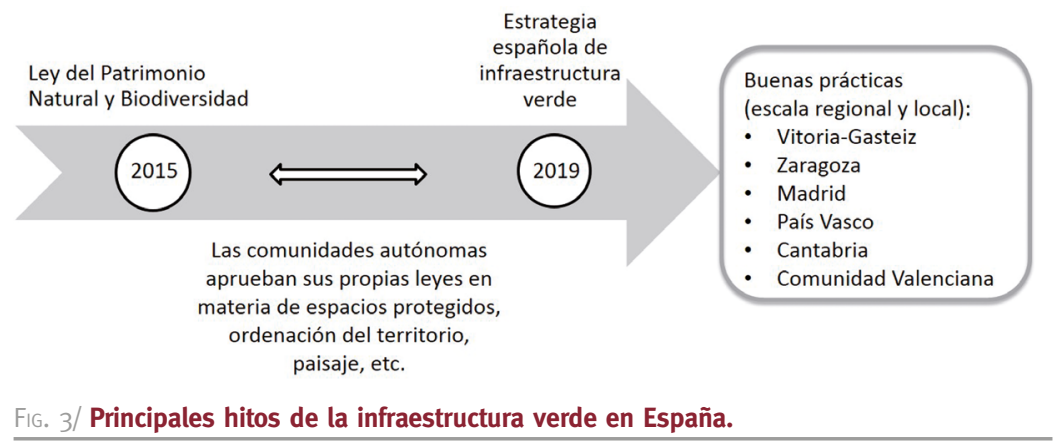

Fuente: Elaboración propia.

\footnotetext{
${ }^{1}$ Ley $33 / 2015$, de 21 de septiembre, por la que se modifica la Ley
}

42/2007, de 13 de diciembre, de Patrimonio Natural y Biodiversidad. 


\section{Incorporación de la infraestructura verde en los procesos de planificación territorial en España. Estudio regional}

Como se ha señalado, la infraestructura verde es un concepto que puede ser implementado a diferentes escalas y, de hecho, el enfoque adoptado en los instrumentos difiere en función de la escala territorial, dado que se le atribuyen finalidades distintas. Según la AEMA (2011), a escala regional o nacional las infraestructuras verdes aparecen vinculadas a los grandes sistemas interconectados de protección de la naturaleza, y su finalidad es la conservación de los ecosistemas naturales y los procesos ecológicos.

Para estudiar la escala regional, en primer lugar cabe hacer referencia a la distribución competencial: aunque el reparto de competencias en materia ambiental es complejo, las comunidades autónomas son las que ejercen la mayor parte de las competencias ambientales relacionadas con la infraestructura verde (como por ejemplo en conectividad ecológica). En efecto, entre otras cuestiones, las comunidades autónomas llevan trabajando desde los años noventa, junto con el gobierno central, en la declaración y gestión de los espacios que forman parte de la Red Natura 2000. En relación a las competencias en materia territorial, según la Constitución son exclusivas de las comunidades autónomas, y aunque la atribución de las competencias en paisaje es más ambigua, también las han asumido implícitamente y algunas comunidades han aprobado sus propios cuerpos normativos específicos (DE LA CRUZ \& MADURGA, 2019).
Como vemos, las comunidades autónomas son soberanas para implementar una amplia variedad de acciones relacionadas con la infraestructura verde, incluyendo su incorporación a la planificación territorial. El propio marco normativo de las políticas territoriales podría integrar de forma vinculante la conservación de la biodiversidad y la infraestructura verde en los instrumentos de planificación.

En efecto, si nos fijamos en la legislación de ordenación del territorio del conjunto de las comunidades autónomas, se aprecia que la cuestión ambiental ha adoptado progresivamente una mayor relevancia, con referencias expresas al concepto de desarrollo sostenible y, en menor grado, a la protección del paisaje (ELORRIETA \& al., 2016); de este modo, a menudo las leyes incorporan referencias a ciertos componentes de la infraestructura verde. En cambio, las referencias explícitas a la infraestructura verde desde un punto de vista integral son muy escasas. Solo dos leyes mencionan expresamente la infraestructura verde en su articulado y establecen las bases para su ordenación: la ley de Ordenación del Territorio, Urbanismo y Paisaje ${ }^{2}$ de la Comunidad Valenciana, y el anteproyecto de nueva Ley de Ordenación del Territorio de Galicia ${ }^{3}$. En cuanto a legislaciones específicas de paisaje, Cantabria ${ }^{4}$, Cataluña ${ }^{5}$, Galicia ${ }^{6}$ y el País Vasco ${ }^{7}$ disponen hoy en día de normas propias para ordenar y proteger el paisaje, pero dichas legislaciones no hacen mención alguna de la infraestructura verde específicamente, a diferencia de la mencionada ley valenciana, que regula conjuntamente la ordenación del territorio y el paisaje (FIG. 4).

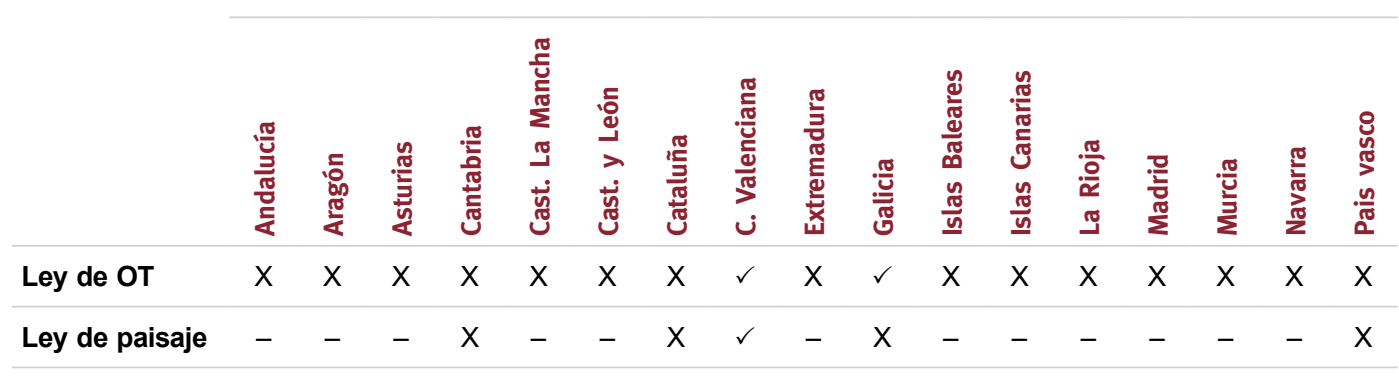

FIG. 4/ Menciones a la infraestructura verde en las leyes de ordenación del territorio y leyes de paisaje de las comunidades autónomas.

Fuente: Elaboración propia.

\footnotetext{
${ }^{2}$ Ley 5/2014 de Ordenación del Territorio, Urbanismo y Paisaje de la Comunidad Valenciana.

${ }^{3}$ Publicado en el DOG 192 del 8 de octubre de 2018.

${ }^{4}$ Ley 4/2014 del Paisaje de Cantabria.

${ }^{5}$ Ley 8/2005, de Protección, Gestión y Ordenación del Paisaje
}

de Cataluña

${ }^{6}$ Ley $7 / 2008$ de Protección del Paisaje de Galicia.

${ }^{7}$ Decreto 90/2014 sobre Protección, Gestión y Ordenación del Paisaje de la Comunidad Autónoma del País Vasco. 
A pesar de que todas las comunidades autónomas tienen su propia ley de ordenación del territorio, que en algunos casos ha sufrido sucesivas modificaciones, en general se han ido desarrollando sin incorporar regulaciones para la infraestructura verde, exceptuando los dos casos arriba mencionados. Llama especialmente la atención la ausencia de la infraestructura verde en las normas más recientes, como la ley de ordenación territorial de Extremadura ${ }^{8}$ de 2018, el anteproyecto de la nueva Ley de Territorio de Cataluña ${ }^{9} \mathrm{o}$ el anteproyecto de Ley de Ordenación del Territorio y Urbanismo de Cantabria ${ }^{10}$, ambos iniciados en 2017.

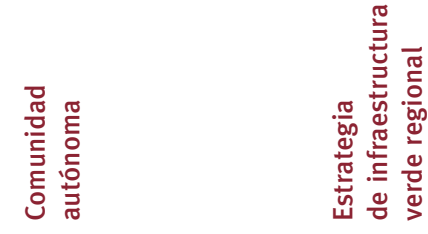

Plan Director para la Mejora de la Conectividad Ecológica. Una estrategia de infraestructura verde (2018)
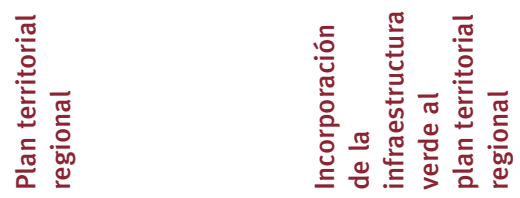

\begin{tabular}{llll}
\hline Andalucía & $\begin{array}{l}\text { Plan Director para la Mejora de la } \\
\text { Conectividad Ecológica. Una estrategia } \\
\text { de infraestructura verde (2018) }\end{array}$ & $\begin{array}{l}\text { Plan de Ordenación del Territorio } \\
\text { de Andalucía (2006) }\end{array}$ \\
\hline Aragón & & $\begin{array}{l}\text { Estrategia de Ordenación Territorial } \\
\text { de Aragón (2014) }\end{array}$ & Indirecta \\
\hline Asturias & & $\begin{array}{l}\text { Directrices Regionales de Ordenación } \\
\text { del Territorio (2016-avance-) }\end{array}$ & Indirecta
\end{tabular}

$\begin{array}{ll}\text { Cantabria } & \text { Plan Regional de Ordenación Territorial Directa } \\ & \text { (2018-aprobación inicial-) }\end{array}$

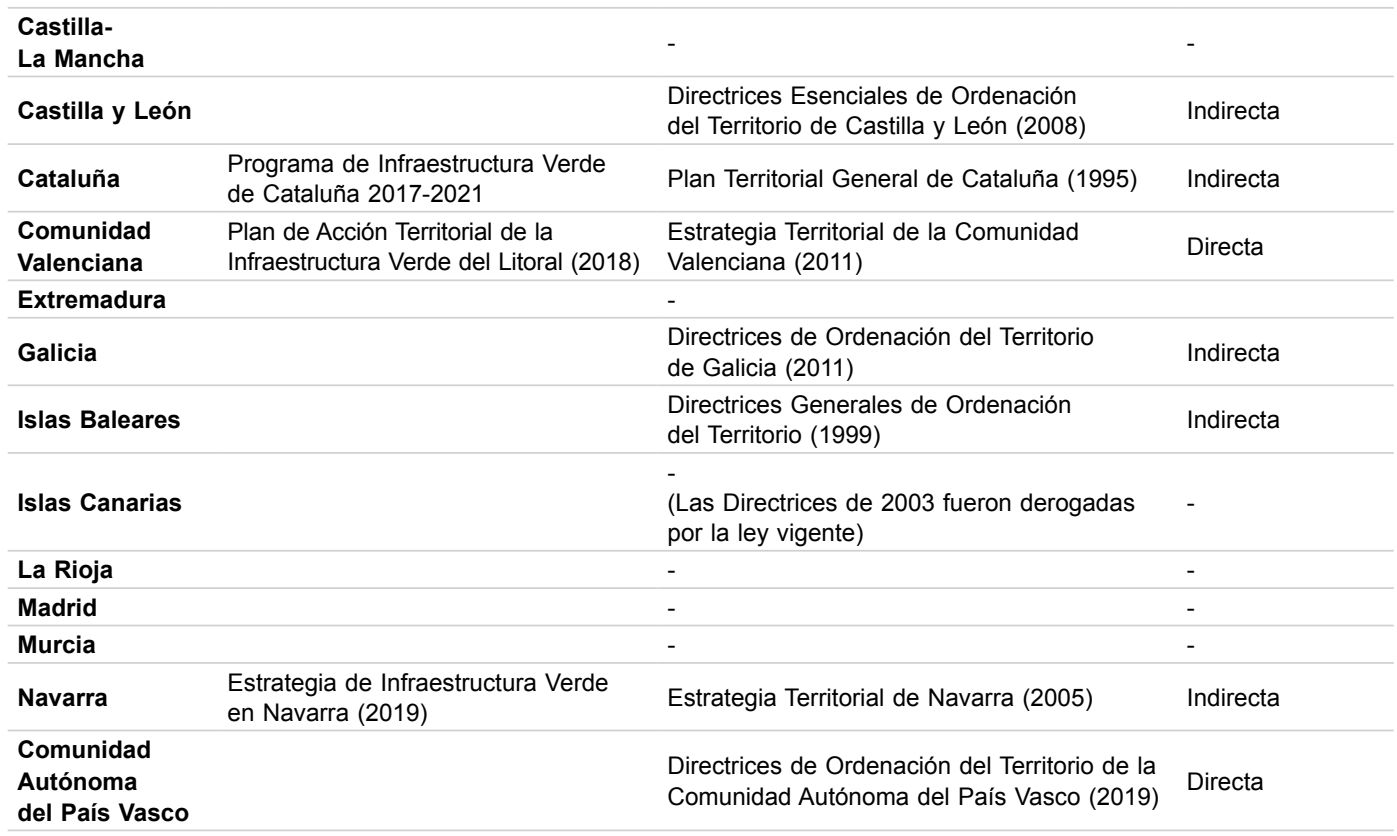

FIG. 5 / Instrumentos específicos de infraestructura verde e incorporación de la infraestructura verde a los instrumentos de planificación territorial en las comunidades autónomas españolas.

Fuente: Elaboración propia.

${ }^{8}$ Ley $11 / 2018$ de Ordenación Territorial y Urbanística Sostenible de Extremadura.

${ }_{9}^{9}$ Publicado en el DOGC 7377 del 25 de mayo de 2017

${ }^{10}$ Publicado en la web de la Dirección General de Urbanismo y Ordenación del Territorio. Disponible en: https://www.territoriodecantabria.es/-/anteproyecto-de-leyordenacion-territorio-y-urbanismo-de-cantabria-pendientede-aprobacion-consejo-gobierno-?inheritRedirect=true 
Más allá del marco legal, es conveniente poner el foco en el marco instrumental creado por las comunidades autónomas. Así, la integración de la infraestructura verde en las políticas territoriales puede realizarse bien a través de instrumentos específicos o bien incorporando la infraestructura verde en los planes de ordenación territorial, y aunque la Estrategia estatal apuesta por la segunda opción (GoBIERNO DE ESPAÑA, 2019), en las comunidades autónomas españolas se han dado ambas formas de integración (ver FIG. 5).

En cuanto a los instrumentos específicos dirigidos a regular la infraestructura verde, todavía son escasos, aunque ciertamente algunas comunidades autónomas han puesto en marcha sus propios planes o programas de forma muy reciente. Entre ellos, destaca el caso de la Comunidad Valenciana, que en 2018 aprobó un Plan de Acción Territorial de la Infraestructura Verde del Litoral, y cuyos avances se analizan en profundidad en un próximo apartado.

Andalucía ha aprobado recientemente un plan de infraestructura verde de carácter territorial, estratégico y transversal (JUNTA DE ANDALUcía, 2018). El plan identifica las áreas estratégicas a escala regional para la conectividad ecológica, y propone medidas que deben aplicarse a través de instrumentos sectoriales.

En el caso de Cataluña, la Generalitat ha impulsado un Programa de Infraestructura Verde a corto plazo como paso previo a la elaboración de su propia estrategia regional. El Programa propone actuaciones de mejora inmediatas y concretas más allá del nivel estratégico (GENERALITAT DE CATALUNYA, 2017). Hasta ahora ya se han dado algunos pasos importantes, como integrar la planificación de la infraestructura verde en la Estrategia del Patrimonio Natural y la Biodiversidad, en el Plan Director Urbanístico Metropolitano (que se encuentra en fase de avance) o cartografiar los servicios ecosistémicos de la provincia de Barcelona.

Finalmente, en la Comunidad Foral de Navarra se publicó en mayo de 2019 una Estrategia de Infraestructura Verde, que tiene su origen en la propia Estrategia Territorial Navarra (GoBIERNO DE NAVARRA, 2019). La Estrategia constituye básicamente una hoja de ruta, que se basa en la identificación y puesta en valor de las funciones de una serie de elementos de la infraestructura verde, y en su correspondiente zonificación.

Por lo que respecta a la integración de la infraestructura verde en los instrumentos de ordenación del territorio, aunque la salvaguarda de los espacios naturales suele ser un elemento importante de ellos, el contexto heterogéneo y fragmentado de las comunidades autónomas (FARINÓs \& ELORRIETA, 2017) hace que sólo algunos planes territoriales de aprobación más reciente hayan incorporado la infraestructura verde en sus regulaciones, y no siempre de forma explícita. Esta incorporación limitada puede estar relacionada con varios factores, como la elaboración tardía (2019) de la Estrategia Estatal, el retraso generalizado en la actualización de las normativas regionales de ordenación territorial, $y$, desde un punto de vista más técnico, la necesidad de disponer de cartografía temática digitalizada en las comunidades autónomas, que permitiría diseñar con mayor facilidad los criterios de utilización de las capas para la configuración de la infraestructura verde y emplearla en la gestión de los suelos de finalidad urbanística. Entre las comunidades que han incorporado la infraestructura verde de forma más directa, destaca de nuevo la Comunidad Valenciana, cuya Estrategia Territorial constituyó un instrumento que incluía elementos como la infraestructura verde y el paisaje. Desde entonces, como decíamos, sólo los planes más recientes han incorporado la infraestructura verde: el Plan Regional de Ordenación Territorial de Cantabria (pendiente de aprobación definitiva) y las nuevas Directrices de Ordenación del Territorio de la Comunidad Autónoma del País Vasco. Estas tres comunidades autónomas son, precisamente, las que se analizan en profundidad en próximos apartados.

En el resto de comunidades autónomas, cuyos planes territoriales ya tienen algunos años de vigencia, la incorporación de la infraestructura verde obligaría a una modificación de dichos documentos ya operativos, con lo que ello puede implicar de alteración de procesos aprobados o de pérdida de oportunidades de transformación del suelo por la falta de definición clara de criterios. Ahora bien, cabe subrayar que a pesar de que no incluyan explícitamente regulaciones para la infraestructura verde, sí ordenan gran parte de sus componentes como los espacios naturales protegidos, los corredores verdes o los espacios fluviales, entre otros (es por ello que la FIG. 5 alude a una incorporación indirecta). Asimismo, algunas comunidades autónomas han incluido también elementos de la infraestructura verde en sus planes de ordenación del litoral o planes territoriales de escala subregional, como los Planes de Ordenación Territorial de Navarra, los Planes Territoriales Parciales de Cataluña o los Planes de Ordenación del Territorio de Andalucía.

\subsection{La infraestructura verde en la Comunidad Valenciana: una apuesta de la administración regional con incipientes efectos prácticos}

La Comunidad Valenciana es un buen ejemplo de contradicción en el conjunto de regiones españolas en materia de ordenación territorial, que 
se manifiesta en las diferencias notables entre las formulaciones teóricas (estrategias y planes) y la realidad urbanística vivida durante las últimas décadas. A partir de la crisis desencadenada en 2008 la administración regional aprueba un nuevo marco de planificación territorial (BuRRIEL DE ORUETA, 2009) que cuestiona en buena medida los principios rectores del anterior modelo de crecimiento urbanístico expansivo y sin apenas límites en el territorio, manejado básicamente desde la escala local (CAPDEPÓN, 2016).

Su franja litoral es, sin duda, el "espacio de conflicto", de interés económico, en materia de planificación territorial y urbanística, al concentrar el porcentaje mayor de población y de actividades económicas, en particular el turismo de sol y playa, motor económico esencial de la economía valenciana (ARIÑO \& GARCÍA, 2018). No es de extrañar, de este modo, que la Comunidad Valenciana encabece la lista de regiones españolas de agresiones al espacio litoral, lo que manifiesta la necesidad de una protección efectiva de la franja litoral y de una gestión real del territorio.

Esta comunidad autónoma inició una nueva etapa en los procesos de ordenación territorial de escala regional y subregional en 2011, con la aprobación de la Estrategia Territorial de la Comunitat Valenciana $^{11}$ (ETCV). En este documento se manifestaba, de forma explícita, la apuesta por una planificación sostenible del espacio geográfico, siguiendo los principios establecidos por la Estrategia Territorial Europea (1999). A ello se sumó la apuesta decidida, en el ámbito europeo, por la gestión del paisaje como herramienta de ordenación del territorio. Así, junto a Cataluña, fue una de las regiones españolas que más temprano aprobó una normativa de planificación territorial que incorporaba la obligación de considerar el paisaje en los procesos de ordenación territorial ${ }^{12}$. Con este marco normativo (revisado y actualizado en $2014^{13}$ y en $2019^{14}$ ) se elaboró y aprobó la Estrategia Territorial de la Comunitat Valenciana que supuso una apuesta decidida por la sostenibilidad del territorio, empleando el paisaje como una herramienta de gestión fundamental.

Junto al paisaje, el otro gran componente de la ordenación del territorio establecido por la Ley de Ordenación territorial de la Comunidad Valenciana es la infraestructura verde. En efecto, la actual Ley de Ordenación del Territorio, Urbanismo y Paisaje incluye en su exposición de motivos, su apuesta decidida por este concepto:

\footnotetext{
11 Decreto $1 / 2011$, de 13 de enero, del Consell, por el que se aprueba la Estrategia Territorial de la Comunitat Valenciana

12 Ley 4/2004, de 30 de junio, de Ordenación del Territorio y Protección del Paisaje.
}

\begin{abstract}
"La definición de la Infraestructura Verde debe ser previa a la planificación de las nuevas demandas de suelo y debe abarcar todas las escalas del territorio..."
\end{abstract}

y dedica un título específico a la infraestructura verde, como método de trabajo en la planificación territorial, a diferente escala (regional, supramunicipal, municipal y urbana), de obligada observancia con carácter previo a la ordenación de usos y actividades en el territorio.

La Estrategia Territorial de la Comunidad Valenciana (Generalitat Valenciana, 2011) señala que uno de los objetivos principales de la política de paisaje es definir la infraestructura verde, a modo de una red interconectada conformada por los paisajes de mayor valor medioambiental, cultural y visual que se convertirá en la estructura básica ecológica. Define la infraestructura verde como una herramienta clave de planificación territorial que debe orientar los crecimientos urbanísticos del futuro preservando el territorio de mayor valor que debe quedar fuera de este proceso urbanizador. Además, la ETCV condiciona los futuros crecimientos de suelo con la capacidad de acogida del territorio, que debe ser definida por la infraestructura verde como fase previa a cualquier desarrollo urbanístico o territorial.

La ETCV ha dado un paso más en la caracterización de la infraestructura verde al incorporar componentes no exclusivamente naturales pero cuya integración cobra sentido al utilizar esta herramienta para la protección de espacios diversos tanto del litoral como de interior. Entiende la infraestructura verde como un sistema de gestión de espacios abiertos integral, que puede contener tanto elementos urbanos como elementos para conectar los espacios verdes de las ciudades con las de su entorno rural (CANTO, 2014), y que se define a partir de una serie de elementos del medio que se detallan más adelante en la Tabla 3 (FIG. 3). La infraestructura verde opera, además, en diferentes escalas de planificación (FIG. 5) al ser un método de trabajo capaz de adaptarse a las realidades territoriales, incluyendo el litoral como espacio de oportunidad y de conflicto.

El mismo año de aprobación de la Estrategia Territorial Valenciana, el gobierno valenciano elaboró un Plan de Acción Territorial (PAT) sobre Infraestructura Verde y Paisaje de la Comunitat Valenciana. Este PAT, que fue un documento muy

\footnotetext{
${ }^{13}$ Ley $5 / 2014$, de 25 de julio, de Ordenación del Territorio, Urbanismo y Paisaje.

${ }^{14}$ Ley $1 / 2019$, de 5 de febrero, de la Generalitat, de modificación de la Ley $5 / 2014$, de 25 de julio, de Ordenación Del Territorio, Urbanismo y Paisaje.
} 
ambicioso y con contenidos de enorme interés para la ordenación del territorio, nunca llegó a aprobarse como tal. Pero el trabajo cartográfico realizado ha pasado a formar parte de las capas existentes en el Sistema de Información Territorial de la Comunidad Valenciana, que incluye una capa específica sobre infraestructura verde de obligada observancia en los procesos de planificación territorial y urbanística ${ }^{15}$.

El último paso en la conexión entre paisaje e infraestructura verde ha sido la elaboración de un documento de Objetivos de Calidad e Instrucciones Técnicas para la ordenación y gestión de los Paisajes de Relevancia Regional de la Comunitat Valenciana (Generalitat Valenciana, 2019) ${ }^{16}$. La intención de este documento es facilitar los criterios que permitan la ordenación y gestión de los Paisajes de Relevancia Regional ${ }^{17}$ y su correcta articulación integrando en la infraestructura verde aquellos espacios capaces de conectar ecológica y funcionalmente los lugares más significativos. De manera que es evidente la intención de integración de estas dos herramientas de ordenación del territorio (unidades paisajísticas e infraestructura verde).

En general, la infraestructura verde es un elemento propio de los planes de acción territorial, que tienen, entre otras funciones, la definición de la infraestructura verde en su ámbito de actuación y han de establecer fórmulas participativas de gestión (CANTO, 2014). Pero la plasmación concreta del uso de la infraestructura verde como herramienta principal de la ordenación del territorio en la Comunidad Valenciana ha venido de la mano de la redacción y aprobación del PATIVEL, Plan de Acción Territorial de Infraestructura Verde del Litoral de la Comunidad Valenciana (Generalitat Valenciana, 2018). Ha sido una apuesta valiente del gobierno valenciano porque afecta al espacio geográfico de mayor deseo de transformación para uso urbano y con mayor valor económico.

Debe recordarse, como antecedente de este plan, que, en 2002, el gobierno autonómico presentó una Estrategia Valenciana para la Gestión Integrada de la Costa, que se apuntaba como la base de la política de la Generalitat Valenciana en este campo (Generalitat Valenciana, 2002). Sin embargo, no tuvo el desarrollo posterior esperado y, en conjunto, se puede afirmar que la región no ha contado con una política de gobierno especifica

\footnotetext{
15 Vid. esta capa de "infraestructura verde" en el visor carto-
gráfico de la Generalitat Valenciana. Disponible en: http://visor.gva.es/visor/. Consultado: agosto 2019.

${ }^{16}$ Este documento está en fase de exposición pública, desde el 6 de septiembre de 2019. La segunda fase, tras la aprobación del mismo, será la redacción de una instrucción
}

en materia de gestión integrada de áreas litorales, por lo menos de manera explícita.

No ha sido, por tanto, hasta la aprobación del PATIVEL cuando la Comunidad Valenciana ha aprobado un texto normativo que avala la gestión integrada del litoral, sumándose así a las iniciativas desarrolladas en otros territorios litorales de nuestro país. Incluso se ha ido más allá al apostar por la protección del paisaje y la definición precisa de la infraestructura verde para este espacio geográfico singular y complejo (VERARebollo \& al., 2019). El PATIVEL es un instrumento de ordenación del territorio de ámbito supramunicipal diseñado desde la urgencia y el pragmatismo para tratar de conseguir la rápida protección de determinados suelos de clara apetencia económica, mediante la aplicación de los principios y filosofía que propone la ordenación de la infraestructura verde.

Las áreas de protección seleccionadas pretenden evitar la consolidación de continuos edificados y de barreras urbanas; esto es, se intenta conservar las últimas ventanas de suelo potencialmente urbanizable que están sin urbanizar en la costa valenciana. Y ello bajo una doble finalidad: la protección y conservación de paisajes y entornos naturales, pero también la utilización de esta protección como oferta turística de calidad.

Acorde con los principios de ordenación integrada del espacio litoral y no solo de la estricta franja costera, este plan afecta a 3 ámbitos (ver FIG. 6) definidos a partir de su distancia, tierra adentro, de la línea de costa (GENERALITAT VALENCIANA, 2018):

a. Ámbito estricto, que comprende los suelos de los municipios litorales situados en la franja de 500 metros de amplitud medida en proyección horizontal tierra adentro desde el límite interior de la ribera del mar y coincidente con el área de influencia de la legislación de costas.

b. Ámbito ampliado, hasta los 1.000 metros de amplitud medida en proyección horizontal tierra adentro desde el límite interior de la ribera del mar, que dota de refuerzo y continuidad ecológica, funcional y visual a los suelos definidos en el apartado anterior y garantiza la amortiguación de los impactos sobre los mismos.

técnica de utilidad para las administraciones públicas

17 Se han identificado 40 Paisajes de Relevancia Regional (PRR) que se agrupan en 14 grandes conjuntos paisajísticos. Disponible en: http://politicaterritorial.gva.es/es/web/ planificacion-territorial-e-infraestructura-verde/paisatges-derellevancia-regional. Consultado: agosto 2019. 
c. Ámbito de conexión, hasta los 2.000 metros de amplitud medida en proyección horizontal tierra adentro desde el límite interior de la ribera del mar, donde se analizará, ordenará y garantizará la conectividad ecológica y funcional del espacio litoral con el resto del territorio.

En el PATIVEL se han aplicado los componentes de la infraestructura verde definidos inicialmente en la Estrategia Territorial de la Comunidad Valenciana, que se estructura en una serie de componentes principales que forman los pilares básicos (en esencia, los espacios naturales con protección), unos servicios ambientales (forestales y agrícolas), unos espacios de especial atención (contaminación, riesgos), unos conectores y una infraestructura verde de escala urbana (parque, paseos, plazas). No obstante, se han incorporado algunos nuevos, como criterio para la delimitación de los ámbitos de protección: los espacios de la zona marina, los espacios costeros de interés ambiental y cultural, y las áreas de influencia del cambio climático en la franja litoral (subida del nivel del mar, áreas de inundación por incremento de episodios de crecida fluvial). En este último aspecto, el PATIVEL resulta novedoso a escala estatal. Para ello ha tenido en cuenta, entre otros, el Informe de efectos del cambio climático en la costa española, avalado por el Ministerio de Transición Ecológica (LOSADA \& al., 2014), para estimar la evolución de la costa valenciana en un doble sentido: erosión por deriva litoral y efectos de temporales marítimos. Se ha preparado, además, una cartografía de detalle de los espacios costeros situados por debajo de $1 \mathrm{~m}$. sobre el nivel del mar, para determinar áreas conflictivas por subida del nivel del mar previsto en la costa valenciana en el señalado informe del Ministerio de Transición Ecológica.

Los suelos regulados con mayor detalle, en tanto son los específicos de este plan, son los que el PATIVEL define como suelos "no urbanizables de protección del litoral" y suelos "no urbanizables de refuerzo del litoral". Estos suelos podrán incorporarse a la red primaria de zonas verdes del municipio y ser adscritos a los procesos de gestión urbanística del planeamiento municipal. Por su parte, los suelos "no urbanizables de refuerzo del litoral", son los que refuerzan la protección de los suelos de la categoría precedente dotándoles de continuidad física y funcional.

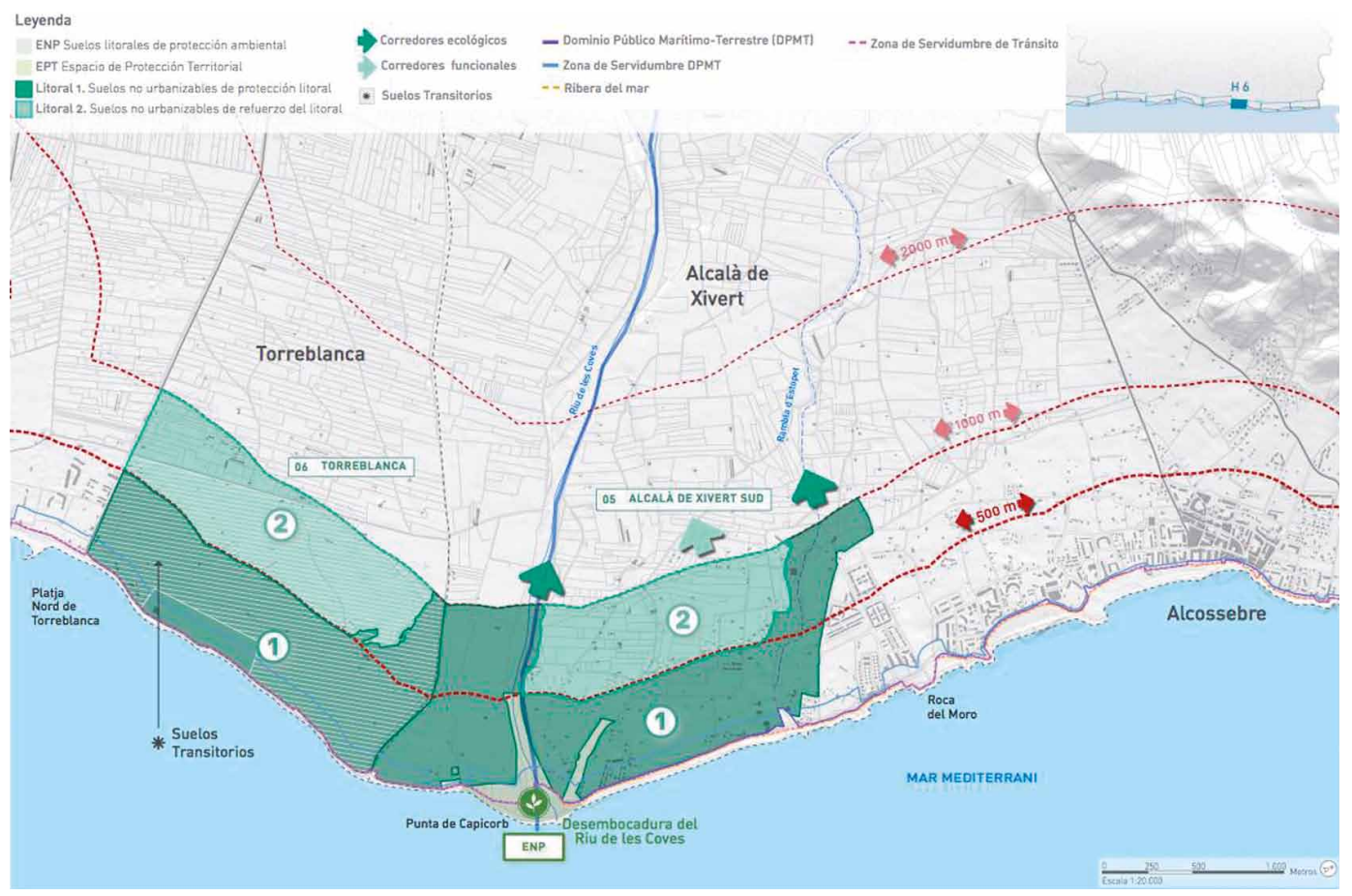

FIG. 6/ Plano de ordenación con tipología de suelos de protección. Sector de Cabanes-Torreblanca (Castellón). 
Como acción concreta, de importancia normativa, el PATIVEL ha delimitado 52 áreas que deben preservarse libres de edificación, como piezas clave de la infraestructura verde del litoral (Generalitat Valenciana, 2018) y que suponen, además de la protección de áreas que ya estaban declaradas como suelo no urbanizable, la desclasificación urbanística de 1.426 has de suelo en la franja litoral. Es decir, de suelos que podrían haberse urbanizado (VerA-Rebollo \& OLCINA, 2017). En su conjunto, el PATIVEL prevé la protección de un total de 7.500 ha del litoral de la región, cifra que integra el $12 \%$ de los suelos que aún no han sido urbanizados en la franja de $500 \mathrm{~m}$ desde el límite interior de la ribera del mar. Como novedad en la política de valorización del litoral, el PATIVEL incluye un catálogo de playas, basado en la diferenciación entre playas urbanas y naturales con su correspondiente normativa de usos y ocupaciones, e incorpora la delimitación y trazado de la Vía del Litoral de la Comunitat Valenciana, definida como un eje estructural que articule los núcleos costeros y que formará parte de la infraestructura verde del litoral.

\subsection{La infraestructura verde en la Comunidad Autónoma del País Vasco: un momento oportuno para su integración en la ordenación del territorio}

La Comunidad Autónoma del País Vasco (CAPV) es un territorio de orografía accidentada cuyo medio físico ha condicionado indudablemente el modelo de ocupación. Se trata de una comunidad autónoma de reducido tamaño y alta densidad de población, que ha evolucionado hacia una ciudad región en la que los límites de los centros y las funciones y actividades se difunden por territorios cada vez más amplios y diversos (Gobierno VAsco, 2019).

A pesar de la gran riqueza y diversidad de sus ecosistemas, en la actualidad es un territorio altamente fragmentado, debido principalmente al desarrollo de grandes infraestructuras lineales que han roto la continuidad ecológica entre espacios naturales. Asimismo, el crecimiento económico e inmobiliario entre los años 1995 y 2007 llevó a una expansión del suelo urbanizado con usos residenciales e industriales. En definitiva, las presiones sobre el medio físico en las últimas dos décadas han sido notables, hasta el punto de que se han intensificado algunos riesgos (como las inundaciones) para la población, que ocupa frecuentemente las áreas próximas a los cauces de los ríos y a sus desembocaduras.
En un territorio con estas particularidades, las políticas ambientales y de ordenación del territorio adquieren una especial relevancia. De hecho, paralelamente a las profundas transformaciones territoriales, las últimas décadas han dejado un importante despliegue de políticas públicas de protección ambiental, así como un amplio legado de instrumentos de planificación territorial. Además, actualmente se está tramitando el Anteproyecto de Ley de Cambio Climático del País Vasco, que prevé la incorporación de determinaciones relacionadas con el cambio climático en los instrumentos de ordenación territorial y urbanismo.

La CAPV ha sido una de las precursoras de la adopción de criterios de desarrollo sostenible en sus políticas territoriales y urbanísticas (ELORRIETA \& al., 2016), caracterizados inicialmente por un sesgo más bien ambientalista, con un enfoque de ordenación del medio físico y de los recursos naturales. El instrumento de planificación regional, que fue uno de los primeros planes territoriales regionales aprobados en el Estado español, ya dejó de manifiesto esta apuesta por la preservación del medio natural, incluso como elemento identitario ligado a la cultura vasca. Las denominadas Directrices de Ordenación Territorial (DOT) estaban reguladas por la Ley $4 / 1990$ de Ordenación del Territorio del País Vasco, y fueron aprobadas en 1997 como resultado de un largo proceso. El documento final se decantó por un carácter eminentemente estratégico y flexible, de ahí que la mayor parte de su contenido se caracterizara por una cierta indefinición bajo la forma de criterios, referencias y pautas de actuación generales (BENABENT, 2006). No obstante, como ya se ha señalado, las DOT como instrumento de ordenación del territorio mostraron una temprana preocupación por los aspectos ambientales, ya que incluyeron objetivos claros de integración de lo ambiental en la ordenación de usos del suelo (JAUREGUI \& ERQUICIA, 1992), siendo el primer instrumento regional español que estableció claramente como objetivo la planificación sostenible del suelo y de los paisajes (ELoRRIETA \& al., 2016). Asimismo, pese a ser anteriores a la publicación del Convenio Europeo del Paisaje y al Decreto 90/2014 sobre protección, gestión y ordenación del paisaje de la CAPV, ya reconocían el valor del paisaje y preveian que los planes subregionales identificaran la necesidad de tratamientos paisajísticos especiales y concretaran los estudios específicos para actuaciones que pudiera alterar el paisaje (URIARTE, 2014).

En el momento de su aprobación se preveía que se llevara a cabo una revisión de las Directrices al cabo de 8 años, cosa que en realidad no se produjo hasta 2019 , cuando las antiguas Directrices habían quedado manifiestamente obsoletas. 
Así, la aprobación definitiva ${ }^{18}$ llegaría después de nada menos que veintidós años de vigencia de las anteriores Directrices. Las nuevas DOT fueron publicadas bajo el ambicioso epígrafe "Lurraldea 2040" (Territorio 2040), como pretendiendo evocar un enfoque estratégico y un espíritu de innovación y anticipación a las futuras transformaciones del territorio.

A pesar de este retraso en la revisión de las DOT, lo cierto es que la ordenación del territorio de la CAPV ha sufrido un gran impulso en los últimos años, gracias a la aprobación de los planes de escala subregional; y también se han impulsado múltiples iniciativas en materia de paisaje, que ha experimentado un gran desarrollo normativo e instrumental. En cuanto a la planificación subregional, el mapa de los quince Planes Territoriales Parciales (PTP) está prácticamente completado, a falta de la aprobación definitiva del PTP de Tolosaldea. Los PTP son los encargados de concretar y ampliar las directrices regionales a la escala comarcal, así como establecer los criterios objetivos para el cumplimiento de las determinaciones de las DOT en la escala local; es por ello que, a la hora de territorializar las propuestas, han adquirido una mayor relevancia.

La nueva generación de planes territoriales es fiel al enfoque ambiental que instauraron las primeras DOT allá en los años noventa, profundizando en algunas materias y avanzando en nuevos conceptos. La mencionada revisión de las DOT, en efecto, presenta una clara vocación ambiental, aunque sigue distinguiendo entre simples recomendaciones y directrices vinculantes de ordenación y uso del espacio, y algunas cuestiones ambientales (como el paisaje o la adaptación al cambio climático) no adquieren el grado de obligatoriedad. También se han incorporado de forma decidida cuestiones relacionadas con la infraestructura verde y los servicios de los ecosistemas. De hecho, el tratamiento de la infraestructura verde como parte de la ordenación del medio físico, junto con la puesta en valor de los servicios de los ecosistemas, es el primero de los diez principios rectores de la revisión de las DOT. Así, las DOT siguen abiertamente la línea marcada por las instituciones europeas e internacionales en la identificación de los principales retos territoriales y ambientales.

En realidad el Gobierno Vasco ya había anticipado algunos trabajos para incorporar la infraestructura verde a los instrumentos de planificación territorial y urbanística. En 2016 se publicó la Metodología para identificación y representación cartográfica de la infraestructura verde, mientras que dos años más tarde, la Cátedra UNESCO de

\footnotetext{
18 Decreto 128/2019, de 30 de julio, por el que se aprueban definitivamente las Directrices de Ordenación Territorial de
}

Sostenibilidad, con financiación del Gobierno Vasco y de la Diputación Foral de Bizkaia, publicó la Guía metodológica para el cartografiado de los Servicios de los Ecosistemas de Euskadi. Estos trabajos serían fundamentales para integrar la infraestructura verde en la revisión de las DOT. Asimismo, se prevé que sean los Planes de acción del paisaje los que protagonicen la introducción de la infraestructura verde en el planeamiento territorial y urbanístico en la escala local (URIARTE, 2014), poniendo de relieve el vínculo entre políticas territoriales, paisaje e infraestructura verde.

La incorporación de la infraestructura verde en las Directrices regionales se da a lo largo de los diferentes apartados y documentos, desde las propias bases del modelo territorial, hasta las Normas de Aplicación. La Memoria dispone un apartado dedicado a la descripción y análisis del medio físico y la infraestructura verde de la CAPV, donde se manifiesta que la infraestructura verde forma parte del modelo territorial de las DOT y se remite a los anexos a la Memoria para conocer sus componentes, así como un enlace a la cartografía disponible en el geovisor del Gobierno Vasco. Concretamente, la infraestructura verde de la CAPV se compone de los elementos recogidos más adelante en la Tabla 3 (FIG. 3).

Las DOT se trazan como objetivos para la infraestructura verde y los servicios ecosistémicos los siguientes aspectos (GoBIERNO VASCO, 2019: 68): mantener y enriquecer el patrimonio natural y los servicios de la naturaleza; poner en valor los servicios de los ecosistemas como herramienta de gestión sostenible del territorio; integrar los elementos de la infraestructura verde en una red regional e integrar los espacios protegidos en una sola figura de protección; y cultivar los efectos positivos de la infraestructura verde (como la conectividad ecológica, la reducción de los riesgos ante catástrofes, la suficiencia y seguridad alimentaria, la preservación del paisaje, etc.).

Tal y como apunta el tercer objetivo, las DOT subrayan que en algunos espacios que forman parte de la infraestructura verde se solapan diversas figuras de protección, por lo que apuestan por integrarlos en una figura única en el futuro, más allá de mejorar la coordinación entre las figuras existentes. Además, reconocen la necesidad de una mayor interconexión entre los espacios protegidos, a través de la red de corredores ecológicos y de otros espacios de interés natural multifuncionales. Para los corredores ecológicos, identifican también los obstáculos críticos y zonas de conflicto que ponen en riesgo la funcionalidad de estos corredores, y proponen medidas de actuación para mitigarlos.

la Comunidad Autónoma del País Vasco. 
Por otro lado, las Normas de Aplicación dedican el Artículo 4 a las directrices en materia de infraestructura verde y servicios de los ecosistemas, también completadas por un anexo que recoge las categorías de ordenación del medio físico en función de su vocación, así como la regulación de usos de cada categoría. Las directrices en materia de infraestructura verde se caracterizan por un carácter inclusivo, flexible y estratégico, estableciendo ciertos criterios para aplicar las normas reguladoras de los espacios que la componen, realizar un seguimiento de su estado, e identificar y resolver posibles conflictos con la infraestructura gris o con otros usos del territorio.

Al igual que en el caso de la Comunidad Valenciana, las directrices sobre infraestructura verde son especificas para cada escala territorial (FIG. 5). En cuanto a los componentes de la infraestructura verde, las DOT establecen que los planeamientos territoriales y urbanísticos extenderán la red de infraestructura verde incorporando espacios relevantes en sus respectivas escalas, teniendo en cuenta otros espacios protegidos que no están en la infraestructura verde a nivel de la CAPV (como por ejemplo Lugares de Interés Geológico o el Registro de Zonas Protegidas de los Planes Hidrológicos, entre otros). Así, las DOT atribuyen ciertas funciones específicas no sólo al planeamiento urbanístico sino también al subregional, materializado en los Planes Territoriales Parciales.

El cambio climático es considerado en las DOT una cuestión transversal, por su influencia en las tres dimensiones de la sostenibilidad (la ambiental, la social y la económica). Entre las directrices relacionadas con el cambio climático se incluye también la de promover la infraestructura verde como medida de adaptación, así como restaurar los ecosistemas para mantener la resiliencia del territorio.

\subsection{La infraestructura verde en Cantabria: incorporación a una política territorial accidentada}

En Cantabria ha tenido lugar en las dos últimas décadas un importante proceso de urbanización y artificialización del suelo. La mayor parte del crecimiento urbanístico, además, se ha producido en modo de tejido urbano discontinuo y en la franja costera (DELGADO, 2010), con la consiguiente transformación de sus paisajes y ocupación de suelo. La principal causa de ello ha sido la expansión de las urbanizaciones y viviendas de segunda residencia asociadas al turismo y a la construcción de la autovía A-8. Así, la protección

\footnotetext{
${ }^{19}$ Ley de Cantabria 2/2004, de 27 de septiembre, del Plan
}

de los espacios naturales de la comunidad ha mostrado importantes carencias y deficiencias (Delgado, 2012), como la ausencia de instrumentos de ordenación de los recursos naturales o la modificación de los instrumentos de ordenación y protección ambiental existentes para sortear los problemas legales de ciertas urbanizaciones.

En efecto, a pesar de las problemáticas ambientales y paisajísticas existentes, durante más de quince años la normativa elaborada en relación con la ordenación territorial y urbanística tuvo un carácter meramente reactivo, ya que su objetivo fue, ante todo, la adaptación a la legislación estatal en esta materia y prácticamente no se articularon instrumentos propios. Así, durante varias décadas sólo existió en la Comunidad el planeamiento de escala municipal. En 2001 se aprobó la Ley 2/2001 de Ordenación Territorial y Régimen Urbanístico del Suelo de Cantabria, con un marcado carácter urbanístico, que sustituyó a la anterior legislación de 1990. Esta legislación territorial sufriría, en los años posteriores, varias modificaciones, generalmente más laxas y permisivas con las iniciativas urbanizadoras, que por lo tanto supusieron una reducción del nivel de protección de los espacios rurales y naturales. Actualmente se está tramitando un nuevo marco legal, que continúa apostando por legislar conjuntamente las competencias en ordenación del territorio y en urbanismo, y crea nuevos instrumentos de planificación, ya sea para los ámbitos subregionales como para determinadas materias sectoriales con incidencia territorial (RANDO, 2019).

El desarrollo tardío de las competencias en ordenación del territorio ha hecho que en Cantabria los instrumentos de planificación existentes sean considerablemente actuales, aunque también escasos e insuficientes (DELGADO, 2010). El primer instrumento de planificación la Ley 2/2001 llegaría en 2004 con el Plan de Ordenación del Litoral (POL) de Cantabria, que fue aprobado con rango de ley ${ }^{19}$. EI POL tuvo la virtud de formalizarse como primer instrumento de ordenación territorial de Cantabria en un momento en que prevalecía la cultura desarrollista, permitiendo paralizar determinados procesos urbanizadores que de otro modo habrían resultado irreversibles. A día de hoy este plan constituye, probablemente, el instrumento de ordenación territorial en vigor más importante con el que cuenta la comunidad autónoma, pues aún no ha sido aprobado el Plan Regional de Ordenación Territorial (PROT), y según la legislación, los fines y el contenido de ambos planes coinciden a rasgos generales.

Con la aprobación del POL y de las Normas Urbanísticas Regionales previamente al plan regional, 
se deduce que en Cantabria la aprobación de instrumentos de ordenación territorial ha seguido el sentido inverso a la cascada de planificación. El retraso en la aprobación del PROT ha representado, sin duda, un serio obstáculo para el desarrollo de una verdadera política de gestión y protección del territorio y del paisaje en la región. Actualmente, sin embargo, el PROT se encuentra en proceso de tramitación, y el paisaje posee una legislación específica ${ }^{20}$ desde 2014.

En abril de 2018 se produjo la aprobación inicial del PROT, que viene acompañado de un anteproyecto de ley del PROT que establece aspectos tales como su vigencia, contenido o desarrollo a escalas subregionales. Este plan será el encargado de establecer las pautas generales para alcanzar el modelo territorial deseado a escala regional, que parte de dos fundamentos generales: por un lado, el desarrollo de un sistema equilibrado y policéntrico de ciudades, y por otro, la protección del medio natural y la gestión del patrimonio. Así, se aprecia que el patrimonio natural y el paisaje tienen un papel relevante a lo largo del documento.

La infraestructura verde es tratada como parte del patrimonio natural en la memoria de ordenación del PROT. En el análisis y diagnóstico no adquiere demasiado protagonismo, de manera que no se realiza una evaluación específica de la infraestructura verde existente, sino que su futura consolidación se identifica como una oportunidad para la región. EI PROT reconoce, además, que la consolidación de la infraestructura verde apenas se ha empezado a trabajar en Cantabria (Gobierno de CANTABRIA, 2018: 35).

Ante estas carencias, las bases del modelo territorial contemplan la creación y desarrollo de una infraestructura verde regional como medida de valorización del patrimonio natural, regulando el uso eficiente del suelo desde su propia vocación y desterrando la visión residual del suelo rústico o espacio abierto (VEGA \& al., 2019). Las determinaciones más específicas para la infraestructura verde se recogen en el título sobre el patrimonio natural, si bien la clasificación de componentes y espacios resulta algo confusa pues existen diferentes divisiones en función de criterios como la escala, los componentes de la conectividad o el servicio ecosistémico que presta cada espacio.

En términos generales el PROT distingue dos tipos de espacios (FIG. 3): los núcleos, asociados a los biotopos bien conservados, y los conectores, que dan soporte a los ecosistemas integrados en los núcleos, conectándolos a escala regional y local. En realidad los componentes de la infraestructura verde no son definidos como espacios concretos en el PROT, a diferencia de lo que se definía en los otros planes territoriales estudiados, sino que se indica que formarán parte de ella todos aquellos espacios que prestan determinados servicios ecosistémicos. Así, la infraestructura verde se asocia a espacios terrestres o acuáticos que presten los siguientes servicios: conservación de la biodiversidad; conectividad ecológica; almacenamiento y captura de carbono; abastecimiento de alimentos; almacenamiento, suministro y regulación de los flujos de agua; y defensa del litoral. La cartografía donde se distingue la infraestructura verde también la clasifica según estas funciones, de manera que incluye espacios tales como corredores ecológicos, formaciones vegetales arboladas, terrenos de alta productividad agrícola, y masas de agua naturales o artificiales, entre otros.

EI PROT establece unos criterios generales para la regulación de usos en la infraestructura verde, pero también específicos para cada tipo de espacio, según el servicio ecosistémico que presten y según sean espacios núcleo o conectores. Las actuaciones a impulsar por las administraciones en los espacios núcleo van en la línea de la protección, conservación, uso sostenible de los recursos y potenciación de los servicios ecosistémicos, mientras que en los conectores se centran en mejorar los biotopos existentes, fomentar las repoblaciones forestales y, de nuevo, incentivar las actividades que aporten servicios ecosistémicos.

Aunque la infraestructura verde del PROT se entiende a nivel regional, también se indica que ésta debe ser completada y concretada a nivel local mediante los instrumentos propios de la planificación de mayor detalle o urbanística. De este modo, la infraestructura verde se conforma en una red continua y coherente que se desarrolla en tres escalas principales: regional, de cuenca y local. La escala regional o territorial tiene una implantación geográfica que rebasa el ámbito regional y transciende a un contexto supramunicipal; la escala de cuenca se desarrolla en el el ámbito de las cuencas hidrográficas y los elementos asociados a ellas; mientras que la escala local tendrá un desarrollo posterior a través del planeamiento urbanístico municipal.

Las determinaciones del PROT también incluyen la relación entre infraestructura verde y cambio climático, pues pretenden impulsar la infraestructura verde y las soluciones basadas en la naturaleza como medidas de adaptación al cambio

${ }^{20}$ Ley 4/2014, de 22 de diciembre, del Paisaje 
climático y a la sostenibilidad de los recursos naturales. En cambio, el apartado sobre la ordenación del paisaje, que tiene también un capítulo específico, no menciona explícitamente la relación con la infraestructura verde.

\subsection{Discusión y análisis comparado}

Las comunidades autónomas analizadas en los documentos de ordenación territorial aprobados manifiestan su apuesta defintiva en la incorporación de la infraestructura verde en sus procesos de planificación territorial integrada de escala regional. La Comunidad Valenciana, además, cuenta con un plan regional sectorial, el PATIVEL, que ha dado un paso más en la consideración de la infraestructura verde como herramienta efectiva de gestión territorial.
No obstante, hay que recordar que a pesar del enfoque innovador del PATIVEL para la protección de las zonas costeras, la mera declaración legal de protección de un área concreta por sí sola en un no garantiza su buena conservación, pues la viabilidad de una protección basada en la infraestructura verde pasa por la necesaria gestión efectiva y real de esa porción del espacio geográfico a diversas escalas de manera coherente e interrelacionada (PADILLA \& al., 2019), incorporando propuestas para la gestión de los suelos protegidos de manera conjunta entre las administraciones regional y local (VeRA-Rebollo \& al., 2019).

En cuanto a la incorporación de la infraestructura verde a los planes territoriales, ésta se ha dado con ciertas disparidades metodológicas, incluso a la hora de identificar los componentes de la infraestructura verde, como se aprecia en la FIG. 7.

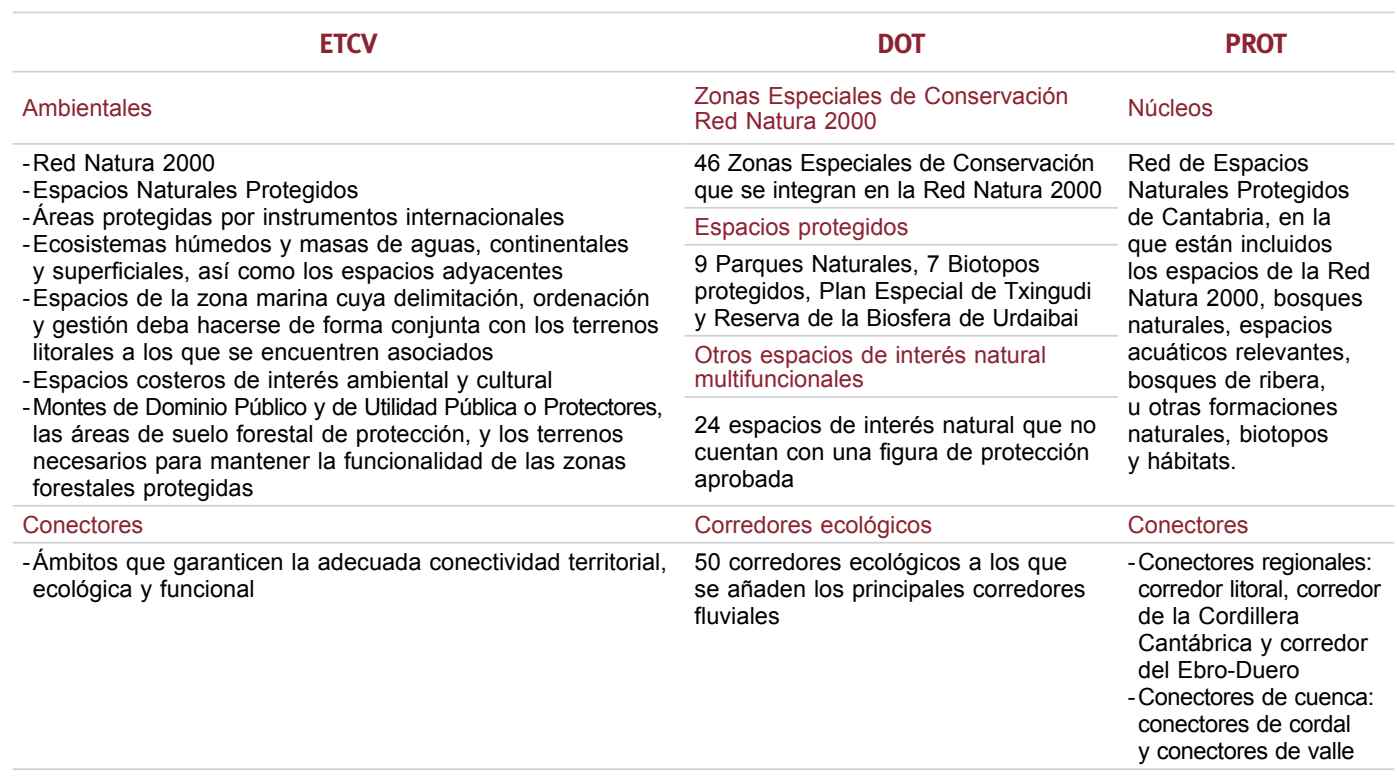

Culturales

-Espacios de elevado valor cultural

- Áreas agrícolas de elevada productividad y funcionalidad

Visuales/Sociales

Espacios de interés paisajístico

Áreas críticas

Zonas críticas respecto a probable incidencia de riesgos naturales

Otros

- Áreas que se definen en el planeamiento territorial, ambiental

y urbanístico por su interés para la conservación del paisaje,

la protección de espacios naturales y la biodiversidad

-Espacios públicos dentro del suelo urbanizado que

la planificación municipal considere relevantes para formar

parte de la infraestructura verde

-Espacios que tengan una cobertura legal ambiental, cultural

o sectorial específica

FIG. 7/ Análisis comparado de los componentes de la infraestructura verde en la ETCV, las DOT y el PROT.

Fuente: Elaboración propia a partir de Generalitat Valenciana (2011), Gobierno Vasco (2019) y Gobierno de Cantabria (2018). 
Esta diversidad de componentes integrantes parece justificada por la propia imprecisión en la definición de la infraestructura verde, como se ha señalado. La ETCV es la que tiene una idea más amplia en relación al tipo de elementos que pueden formar parte de ella, pues se tienen en cuenta componentes muy diversos, desde los ambientales hasta los de tipo cultural. Las DOT, por su parte, se ciñen a criterios básicamente ambientales a la hora de considerar los componentes, aunque la identificación de los espacios es muy rigurosa (con un listado donde son recogidos todos los espacios naturales y corredores que la componen), mientras que dicha identificación en el PROT es sólo indirecta (se cartografían los espacios que prestan determinados servicios ecosistémicos). En cualquier caso, queda en evidencia el potencial de la infraestructura verde para proteger elementos tradicionalmente desatendidos, ya sean elementos del medio natural (como los corredores ecológicos o los espacios sometidos a restauración ecológica), que elementos de carácter más antrópico (como los espacios agrarios o de interés paisajístico).

Por otro lado, en el presente análisis se ha creído interesante realizar una comparación de los elementos integrantes de la infraestructura verde analizados en los tres planes objeto de estudio con los componentes que se listan en la Estrategia española de infraestructura verde, para valorar el nivel de coherencia de los planes regionales con respecto a la Estrategia de nivel superior. Debe tenerse en cuenta en todo caso que los instrumentos analizados en este trabajo son de aprobación reciente, previa a la publicación del borrador de la Estrategia estatal.

La Estrategia española de infraestructura verde propone un total de 56 componentes que formarian parte de la infraestructura verde regional, donde se incluyen espacios naturales, agrarios, montes, $\mathrm{u}$ otro tipo de territorios. En este sentido, la FIG. 8 muestra la presencia o no de estos componentes en los tres planes territoriales regionales estudiados.

Componentes de IV / Comunidad autónoma - plan territorial

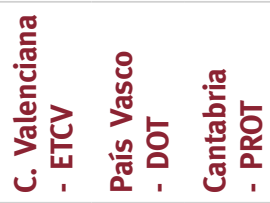

Zonas de Red Natura 2000

1. ZEPA

2. LIC/ZEC

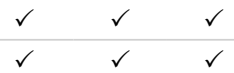

Espacios naturales protegidos

3. Parque nacional

4. Parque natural

5. Monumento Natural

6. Reserva natural

7. Área marina protegida

8. Paisaje Protegido

$\begin{array}{lll}\text { X } & \text { X } & \checkmark \\ \checkmark & \checkmark & \checkmark \\ \checkmark & \text { X } & \checkmark \\ \checkmark & \text { X } & \text { X } \\ \checkmark & \text { X } & \text { X } \\ \checkmark & \text { X } & \checkmark\end{array}$

Áreas protegidas por instrumentos internacionales

9. Humedales de Importancia Internacional, del Convenio relativo a los Humedales de Importancia Internacional especialmente como Hábitat de Aves Acuáticas (RAMSAR).

10. Sitios Naturales de la Lista del Patrimonio Mundial, de la Convención sobre la Protección del Patrimonio Mundial, Cultural y Natural.

11. Áreas protegidas OSPAR, del Convenio para la protección del medio ambiente marino del Atlántico del nordeste (OSPAR).

12. Zonas Especialmente Protegidas de Importancia para el Mediterráneo (ZEPIM), del Convenio para la protección del medio marino y de la región costera del Mediterráneo.

13. Geoparques declarados por la UNESCO.

14. Reserva Biosfera.

15. Reservas biogenéticas del Consejo de Europa.

Protección de Humedales

16. Zonas sensibles a la contaminación por nitratos.

17. Reservas naturales fluviales.

18. Zonas, cuencas o tramos de cuencas, acuíferos o masas de agua de protección especial.

$\begin{array}{lll}\checkmark & \checkmark & \checkmark \\ \checkmark & \checkmark & X \\ X & X & X \\ \checkmark & X & X \\ X & \checkmark & X \\ X & \checkmark & \checkmark \\ X & X & X\end{array}$

$\begin{array}{lll}\checkmark & \checkmark & X \\ X & \checkmark & X \\ X & \checkmark & \checkmark\end{array}$


Componentes de IV / Comunidad autónoma - plan territorial

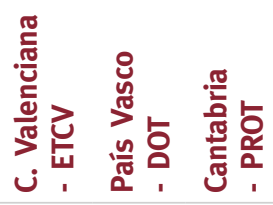

Montes

19. Zonas de Dominio Público forestal.

20. Montes de utilidad pública (MUP)

21. Montes protectores.

22. Montes privados y de socios sometidos a planes de gestión.

$\begin{array}{lll}\text { X } & \text { X } & \text { X } \\ \checkmark & \checkmark & \checkmark \\ \checkmark & \checkmark & \text { X } \\ \text { X } & \text { X } & \text { X } \\ \text { X } & \text { X } & \text { X } \\ \checkmark & \checkmark & \checkmark\end{array}$

23. Montes vecinales en mano común sometidos a planes de gestión.

24. Zonas de alto riesgo de incendio.

Zonas con gestión ambiental de dominio público

25. Zonas de Dominio Público hidráulico.

26. Zonas de Dominio público marítimo-terrestre.

27. Vías Pecuarias.

Espacios sujetos a actividades agrarias protectoras de la biodiversidad

28. Figuras de la PAC: condicionalidad, reverdecimiento, desarrollo rural.

$\begin{array}{lll}\checkmark & \checkmark & \checkmark \\ \checkmark & \checkmark & \checkmark \\ \checkmark & X & X\end{array}$

29. Áreas agrarias y forestales de alto valor natural (High Nature Value Farming-HNV)

30. Espacios sujetos a Contratos territoriales Agrarios

31. Áreas incluidas en Planes de razas autóctonas ganaderas.

32. Territorios con plantaciones para preservación de recursos genéticos.

33. Territorios con plantaciones sumideros de carbono.

34. Áreas con denominaciones de calidad (IGR)

$\begin{array}{lll}X & X & X \\ X & X & X \\ X & X & X \\ X & X & X \\ X & X & X \\ X & X & X \\ X & X & X\end{array}$

Territorios delimitados en figuras de conservación orientadas a especies

35. Especies Silvestres en Régimen de Protección Especial y Especies Amenazadas.

36. Colmenares.

$\begin{array}{lll}X & \checkmark & X \\ X & X & X\end{array}$

Lugares, espacios o enclaves definidos y con objetivos de conservación de biodiversidad

37. Áreas identificadas dentro del Catálogo Español de Hábitats en Peligro de Desaparición.

38. Espacios recogidos en Planes cinegéticos y cotos privados de caza.

\begin{tabular}{lll}
$\checkmark$ & X & X \\
X & X & X \\
X & X & X \\
X & X & X \\
X & X & X \\
X & X & X \\
$\checkmark$ & $\checkmark$ & X \\
$\checkmark$ & $\checkmark$ & $\checkmark$ \\
\hline$\checkmark$ & X & $\checkmark$ \\
\hline X & X & X \\
\hline X & X & X \\
\hline$\checkmark$ & $\checkmark$ & $\checkmark$ \\
\hline X & X & X \\
X & X & X
\end{tabular}

39. Espacios gestionados por Bancos de hábitat o de conservación de la naturaleza.

40. Áreas de conservación comunal.

41. Espacios incluidos en Acuerdos de Custodia del territorio.

42. Territorios en explotación en producción ecológica.

43. Zonas incluidas en el Inventario español de Lugares de Interés Geológico.

44. Cuevas y otras infraestructuras subterráneas.

45. Territorios históricos incluidos como Bienes de Interés Cultural.

46. Zonas donde se realicen acciones de lucha contra la desertificación del PAND.

47. Reservas privadas.

48. Corredores, áreas de montaña y otros elementos de conectividad.

49. Zonas de agricultura de montaña.

50. Reservas marinas de pesca.

Lugares delimitados y gestionados para la conservación de la biodiversidad en los siguientes planes e instrumentos de ordenación

51. Plan hidrológico y planes Hidrológicos de Demarcación.

52. Plan Estratégico del Patrimonio Natural y la Biodiversidad 2011-2017.

53. Plan de ordenación de los Recursos Naturales.

54. Planes de ordenación de los Recursos Forestales.

55. Plan de ordenación territorial y plan urbanístico.

56. Plan y estudio de paisaje (Convenio Europeo).

$\begin{array}{lll}\checkmark & \checkmark & \text { X } \\ \checkmark & \text { X } & \text { X } \\ \checkmark & \checkmark & \text { X } \\ \text { X } & \checkmark & \text { X } \\ \checkmark & \checkmark & \checkmark \\ \checkmark & \checkmark & \checkmark\end{array}$

FIG. 8/ Coherencia de los planes estudiados con los componentes contemplados por la Estrategia Estatal de infraestructura verde. 
Del análisis de la tabla se observa que los planes de la Comunidad Valenciana y la Comunidad Autónoma del País Vasco son los que presentan una mayor coincidencia con los componentes propuestos en la Estrategia estatal (mencionan aproximadamente la mitad de sus componentes). En el PROT de Cantabria, a su vez, se mencionan aproximadamente un tercio de los componentes de la lista de control, lo cual es consecuencia, en gran parte, de la indeterminada identificación de los componentes de su propia infraestructura verde. Además, hay que tener en cuenta que Cantabria tiene un desarrollo instrumental mucho menor en materia territorial y de medio ambiente, lo cual hace que el PROT no pueda fundamentarse en otros planes sectoriales de recursos naturales, forestal, de espacios fluviales, etc. para su propio contenido.

Los espacios naturales que cuentan con alguna figura de protección son, en general, los más claramente reconocibles en los tres planes analizados. Sin embargo, también hay que tomar en consideración que los planes no siempre mencionan exactamente los espacios o figuras de protección recogidos en la Estrategia estatal, simplemente porque, en ejercicio de sus competencias, la comunidad autónoma posee legislación propia y las figuras de protección o referentes derivados de ella son distintos a los estatales. En sentido contrario, los espacios agrarios son los grandes ausentes en los tres planes, aunque sí se suelen tener en cuenta indirectamente como proveedores de servicios ecosistémicos. También se aprecia una presencia desigual de otros enclaves que podrían ser potencialmente importantes para la conservación de la biodiversidad, pero que carecen de figuras de protección específicas o de una regulación pública (como las reservas privadas o las áreas de conservación comunal).

El dominio público (hidráulico, marítimo-terrestre) queda integrado, como elemento destacado, entre los componentes de la infraestructura verde. Por tanto la protección de los valores que integran estas estructuras territoriales al servicio de lo público queda totalmente garantizada en la infraestructura verde. E incluso se amplian sus áreas de influencia, restringuiendo los usos del suelo y amortiguando posibles impactos territoriales.

Por último, es interesante comprobar que los tres planes analizados subrayan el carácter multiescalar de la infraestructura verde, distinguen tres escalas de intervención (ver FIG. 9) y le otorgan funciones específicas a cada escala. En general, la escala local es la encargada de delimitar detalladamente los espacios que componen la infraestructura verde y corregir la posible fragmentación de los mismos, mientras que la regional articula los grandes espacios y corredores y la subregional cumple un papel de conexión entre ambas.

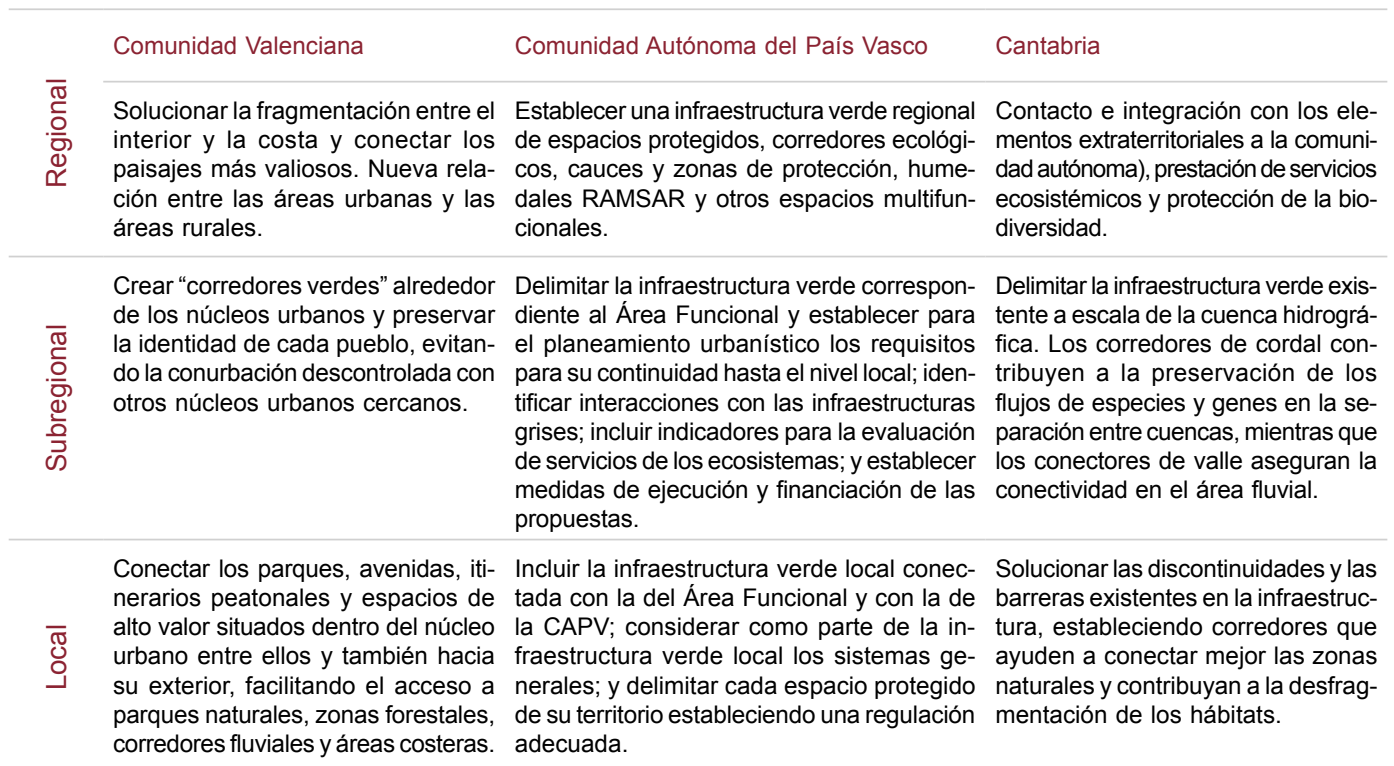

FIG. 9/ Funciones de la infraestructura verde en las diferentes escalas de planificación territorial en la Comunidad Valenciana, Comunidad Autónoma del País Vasco y Cantabria.

Fuente: Elaboración propia a partir de Generalitat Valenciana (2011), Gobierno Vasco (2019) y GobieRno de Cantabria (2018). 
La evaluación del efecto de estos planes es complicada, debido a su juventud. De los tres, tan sólo el PATIVEL está operativo; las DOT del País Vasco se aprobaron en julio de 2019 y las Directrices de Cantabria siguen el trámite de aprobación. En el proceso de tramitación del PATIVEL se presentaron 4.615 recursos por parte de propietarios afectados, ayuntamientos y colectivos profesionales ${ }^{21}$, especialmente en áreas que resultaban conflictivas por sus expectativas de transformación para uso residencial (Alcalá de Xivert, Oliva, Benissa y La Marina-Elx). Aunque ninguno de ellos ha prosperado, se ha conseguido, en un primer momento, detener procesos de urbanización en las áreas protegidas. A raíz de los efectos sufridos en la franja costera valenciana por la borrasca "Gloria" (enero 2020), han surgido algunas voces (colectivos de defensa ambiental, administración municipal) que han sugerido la necesidad de extender los criterios de protección establecidos en el PATIVEL a espacios con suelo urbanizable, y con programa aprobado, e incluso a áreas urbanas de primera línea de costa, cuestión que no entraba en la filosofía inicial del plan y que supone un conflicto de competencias. En 2020, dos años después de su aprobación, no se han desarrollado aún los planes de gestión previstos en la ley ni se ha realizado la propuesta de trazado definitivo de la vía verde litoral contemplada en el plan.

\section{Conclusiones}

El impulso a la infraestructura verde proveniente de la esfera europea ha hecho que su integración en el marco legal y en la planificación territorial de los estados miembros sea ya una realidad, de la cual también hallamos buenos ejemplos en el Estado español. Tras la nueva Ley de Patrimonio Natural y Biodiversidad de 2015 y la reciente publicación del borrador de la Estrategia Estatal de Infraestructura Verde y de la Conectividad y la Restauración Ecológicas, se prevé que las comunidades autónomas procedan a desarrollar sus propias estrategias de escala regional. De hecho, en ejercicio de sus competencias en ordenación del territorio, algunas comunidades han comenzado a integrar la infraestructura verde a sus políticas territoriales, aunque se trata de iniciativas concretas que, por el momento, cubren sólo una parte reducida del mapa estatal.

Esta integración de la infraestructura verde a las políticas territoriales regionales se ha producido por dos vías diferentes: en algunas comunidades

\footnotetext{
${ }^{21}$ Vid. documento elaborado al respecto por la Consellería de Habitatge, Obres Publiques i Vertebració del Territori de la Generalitat Valenciana. Disponible en:
}

se han aprobado estrategias o instrumentos específicos para la ordenación de la infraestructura verde, mientras que en otras, se ha optado por incorporar la infraestructura verde a los instrumentos de ordenación del territorio.

Por el momento las estrategias de infraestructura verde regionales son escasas, algo que resulta coherente si se tiene en cuenta que la Estrategia estatal ha sido presentada muy recientemente y que de ella deben emanar las regulaciones regionales. Aun así, algunas comunidades autónomas como Andalucía, Cataluña, la Comunidad Valenciana y Navarra han tomado la iniciativa poniendo en marcha sus propios planes o programas entre 2017 y 2019 , por lo que los primeros trabajos de infraestructura verde a nivel Estatal han provenido en realidad de las escalas inferiores. EI PATIVEL de la Comunidad Valenciana es un caso destacable, pues a pesar de centrarse en la franja litoral, constituye un documento integral de ordenación y gestión que regula usos del suelo futuros en la escala local. Es además un excelente ejemplo de la anticipación de los efectos del cambio climático en el territorio y el paisaje, puesto que ha incorporado esta variable como elemento integrante de la Infraestructura Verde regional.

En cuanto a los aspectos normativos de ordenación del territorio, la legislación territorial y de paisaje está aún lejos de acoger este nuevo elemento, pues únicamente las leyes de la Comunidad Valenciana (ordenación del territorio, urbanismo y paisaje) y Galicia (ordenación del territorio) aluden a la infraestructura verde. Varias leyes se han aprobado o revisado con posterioridad a la inclusión de la infraestructura verde en el ordenamiento legal estatal, por lo que omitir la infraestructura verde parece a todas luces una oportunidad perdida para la adaptación de la legislación regional a la nueva regulación española y europea.

A pesar de esta ausencia normativa ya existen varios ejemplos de integración de la infraestructura verde en instrumentos de ordenación del territorio de escala regional. En realidad, todos los planes territoriales regulan de una $u$ otra forma al menos una parte de los componentes de la infraestructura verde, aunque la integración explícita o directa es aún tímida en muchos de ellos.

El hecho de optar por la vía de la aprobación de un instrumento específico o la integración de la infraestructura verde en los planes territoriales no parece determinante para la efectividad de su regulación. Más bien resulta fundamental el

http://politicaterritorial.gva.es/documents/20551069/162407502/An álisis+de+las+alegaciones+e+informes+realizados+al+PATIVEL/ adf16e3f-11cf-405c-bfb9-4241413a7881. Consultado: mayo 2020. 
cumplimiento de la jerarquía jurídico-administrativa entre documentos normativos y administraciones competentes. Al igual que en cualquier proceso de planificación, para garantizar la coherencia de las intervenciones sobre el territorio lo más adecuado sería adoptar un proceso de planificación en cascada (PUJADAS \& FONT, 1998), incorporando la infraestructura verde como herramienta para la planificación en las estrategias o directrices territoriales de escala regional y posteriormente implementando su cumplimiento y mejorando sus contenidos (elementos integrantes) en las escalas inferiores (subregional, metropolitana y urbana). Para determinados elementos del medio que requieran un tratamiento específico se puede habilitar, como ha ocurrido en el caso de la Comunidad Valenciana, la redacción de un plan integral sectorial (litoral), teniendo siempre como referencia las determinaciones generales de la estrategia territorial regional. Lo importante es que se reconozca el valor de la infraestructura verde como herramienta para la gestión sostenible del territorio y ello supone una definición precisa de elementos integrantes y criterios de aplicación.

En cuanto a los planes territoriales de las comunidades autónomas que han incorporado la infraestructura verde, la ausencia de unas directrices comunes por parte de la escala europea o estatal en el momento de su elaboración ha contribuido a que presenten diferencias significativas en cuanto al significado y la metodología de planificación de la infraestructura verde en su articulado. Asimismo, los tres planes analizados no son completamente coherentes con las actuales directrices estatales, pues más allá de los espacios naturales protegidos y los corredores ecológicos, otros territorios reciben una atención limitada, como aquellos más antropizados pero con funciones ecosistémicas importantes (espacios agrarios) o los espacios naturales que carecen de figuras de protección específicas o de una regulación pública.

La consideración de la infraestructura verde como herramienta de planificación y gestión en los planes de ordenación territorial es un proceso reciente que tendrá un impulso importante en los próximos años gracias a la aprobación de la Estrategia Estatal de Infraestructura Verde y de la valoración de las bondades de este instrumento como plasmación efectiva de los criterios de sostenibilidad territorial en las escalas regional, subregional y local. Un aspecto fundamental para valorar la efectividad de la infraestructura verde como herramienta de planificación territorial en el futuro inmediato va a ser la conectividad real de espacios naturales o áreas de importancia patrimonial y cultural en el ámbito urbano (planes urbanísticos), que es, seguramente, el aspecto más complejo a desarrollar en la ordenación integral de los territorios. Pueden servir de ejemplo las experiencias desarrolladas en Berlín, con el desarrollo del Biotope Area Factor (BAF), así como, los casos del Space Green Factor en Malmo (Suecia), Seattle Green Factor (EE. UU.), Maryland Green Infraestructure (EE. UU.) o Greening Sydney Plan (Australia). Frente a una planificación física que se ha mostrado poco efectiva para garantizar el desarrollo sostenible especialmente en la escala urbana, la infraestructura verde se muestra ahora como un medio más eficaz para la planificación y gestión sostenible de los territorios.

\section{Bibliografía}

Agencia Europea del Medio Ambiente, Aema (2011): Green infrastructure and territorial cohesion. The concept of green infrastructure and its integration into policies using monitoring systems, Luxemburgo, Luxemburgo, Unión Europea.

ARIÑO, A. (dir.) \& GARCIA, P. (coord.) (2018): La sociedad valenciana en transformación (1975-2025), Valencia, España, Publicaciones de la Universitat de València.

Bardin, L. (2002): Análisis de contenido, Madrid, España, Akal.

Benabent, M. (2006): La Ordenación del Territorio en España, Sevilla, España, Universidad de Sevilla - Consejería de Obras Públicas y Transportes.

Benedict M.A. \& Mc Mahon E.T. (2002): Green infrastructure: smart conservation for the 21st century. Renewable Resources Journal, (20), 12-17.

BREUSTE, J.\& al. (2015): Introduction (special Issue on Green Infrastructure for Urban Sustainability). Journal of Urban Planning and Development, Vol. 141 (3).

Burriel de Orueta, E. L. (2009): La planificación territorial en la Comunidad Valenciana (1986-2009). [En línea]. Scripta Nova. Revista Electrónica de Geografía y Ciencias sociales, Vol. XIII (306). http://www.ub.edu/geocrit/sn/sn-306.htm

Calzada, P. (Dir.) (2019): Guía de infraestructura verde municipal. [En línea]. Red de Gobiernos Locales + Biodiversidad, Federación Española de Municipios y Provincias, Asociación de Empresas de Gestión de Infraestructura Verde, Asociación Española de Parques y Jardines Públicos. http://www.redbiodiversidad.es/sites/default/files/ GUIA Biodiversidad CAPITULOS1 5.pdf

CANTO, M. T. (2014): La planificación y gestión de la Infraestructura Verde en la Comunidad Valenciana. Revista Aragonesa de Administración Pública (43-44), 215-234.

CAPDEPón, M. (2016): Conflictos ambientales derivados de la urbanización turístico-residencial. Un caso aplicado al litoral alicantino. Boletín de la Asociación de Geógrafos Españoles (71), 31-57.

COMISIÓN EUROPEA (2011): Estrategia de la UE sobre la biodiversidad hasta 2020: nuestro seguro de vida y capital natural, Bruselas, Bélgica, Unión Europea.

- (2013): Infraestructura verde: mejora del capital natural de Europa, Bruselas, Bélgica, Unión Europea. 
- (2014): Construir una infraestructura verde para Europa, Bruselas, Bélgica, Unión Europea.

- (2015): Revisión intermedia de la Estrategia de la UE sobre la Biodiversidad hasta 2020, Bruselas, Bélgica, Unión Europea.

- (2019): Revisión de la aplicación de la política medioambiental. Informe de España, Bruselas, Bélgica, Unión Europea.

de LA Cruz, Á., \& Madurga, M. I. (2019): Los Instrumentos de Ordenación del Territorio en España. Estudio comparado de la legislación y los instrumentos vigentes. Ciudad Y Territorio Estudios Territoriales (CyTET), 51(199), 175-200.

https://recyt.fecyt.es/index.php/CyTET/article/ view/76722

Delgado, C. (2010): La ordenación territorial en Cantabria: normas, planes, proyectos y realidades. Cuadernos Geográficos, 47 (2010-2), 453-491.

- (2012): Protección y ordenación del medio natural en Cantabria. Normativa, instrumentos y conflictos territoriales. Boletín de la Asociación de Geógrafos Españoles (60), 115-140.

Elorrieta, B. \& Olcina, J. \& SÁnchez, D. (2016): La sostenibilidad en la planificación territorial de escala regional. Cuadernos Geográficos, 55 (1), 149-175.

FARINós, J. \& EloRRIETA, B. (2017): "La articulación territorial de España: cohesión a partir de una nueva gobernanza". En J. FARINós y J. OLCINA (coords), Geografía regional de España. Espacio y comunidades: bases para una regionalización renovada del territorio español (pp. 563-617), Valencia, España, Tirant lo Blanch.

FARIÑA, J. \& NAREDO, J. M. (Dir.) (2010): Libro blanco de la sostenibilidad en el planeamiento urbanístico español. Madrid, Centro de publicaciones del Ministerio de la Vivienda.

FERIA, J. M. \& SANTIAGO, J. (2017): Naturaleza y ciudad. Perspectivas para la ordenación de la infraestructura verde en los planes territoriales metropolitanos en España. Boletín de la Asociación de Geógrafos Españoles (74), 117-141.

FERnÁNDEZ de GatTA, D. (2018): La Estrategia estatal de infraestructura verde y de la conectividad y restauración ecológicas: un nuevo instrumento para proteger la biodiversidad. Actualidad Jurídica Ambiental (81), 57-120.

García-Blanco, G., Carrao, H. \& Fons, J. (2019): "La Infraestructura Verde en beneficio del desarrollo territorial estratégico: ESPON GRETA". En FUNDICOT, $9^{\circ}$ Congreso Internacional de Ordenación del Territorio: Planificación y gestión integrada como respuesta (pp. 514-531), Madrid, España, FUNDICOT.

Generalitat de Catalunya (2017): Programa d)Infraestructura verda de Catalunya 2017-2021. [En línea]. Generalitat de Catalunya. http://mediambient.gencat.cat/web/.content/home/ ambits dactuacio/avaluacio ambiental/infraestructura verda serveis ecosistemics/infraestructura verda/PIVC v10 144ppi.pdf

Generalitat Valenciana (2002): Estrategia Valenciana para la Gestión Integrada de la Costa, Valencia, España, D.G. de Puertos y Costas de la Consellería de Infraestructuras y Transporte de la Generalitat Valenciana.

- (2011): Estrategia Territorial de la Comunitat
Valenciana, Valencia, España, Consellería de Infraestructuras, Territorio y Medio Ambiente de la Generalitat Valenciana.

- (2018): Plan de Acción Territorial de la Infraestructura Verde del litoral, Valencia, España, Consellería de Vivienda, Obras Públicas y Vertebración del Territorio de la Generalitat Valenciana.

- (2019): Objetivos de Calidad e Instrucciones Técnicas para la ordenación y gestión de los Paisajes de Relevancia Regional de la Comunitat Valenciana, Valencia, España, Consellería de Política Territorial, Obras Públicas y Movilidad.

Gobierno de Cantabria (2018): Plan Regional de Ordenación del Territorio. [En línea]. Gobierno de Cantabria.

http://geoservicios.cantabria.es/Series/Descargas PROT/PROT AprobacionInicial Abril2018/C PLAN/Memoria/PROT 21 Analisis.pdf

Gobierno de España (2019): Estrategia Estatal de Infraestructura Verde y de la Conectividad y la Restauración Ecológicas. Borrador mayo 2019. [En línea]. Ministerio para la Transición Ecológica, Gobierno de España.

https://www.miteco.gob.es/images/es/borradoreeivcre infopublica tcm30-497133.PDF

Gobierno de NavarRa (2019): Estrategia de Infraestructura Verde en Navarra. [En línea]. Gobierno de Navarra.

http://internet.gccpublica.navarra.es/sot/ Documentos/INFRAESTRUCTURA\%20VERDE/ ESTRATEGIA\%20INF\%20VERDE.pdf

GoBIeRno VAsco (2019): Directrices de Ordenación del Territorio de la CAPV, Vitoria, España, Gobierno Vasco - Eusko Jaurlaritza.

Jauregui, P. \& ERquicia, J. M. (1992): Marco de Ordenación Territorial de la Comunidad Autónoma del País Vasco. Rev. Munibe, (44), 61-67.

Jones, M. \& STENSEKE, M. (eds.) (2011): The European Landscape Convention: Challenges of participation, Dordrecht, Holanda, Springer.

JUNTA DE ANDALUcía (2018): Plan director para la mejora de la conectividad ecológica en andalucía. Una estrategia de Infraestructura Verde. Informe de síntesis. [En línea]. Consejería de Medio Ambiente y Ordenación del Territorio, Junta de Andalucía. http://www.juntadeandalucia.es/medioambiente/ portal web/web/temas ambientales/biodiversidad $/ 6$ habitats y ecosistemas $/ 0$ plan conectividad/plan aprobado/PDMCEA sintesis 2018.pdf

LAFORTEZZA, R. \& al. (2013): Green Infrastructure as a tool to support spatial planning in European urban regions. iForest - Biogeosciences and Forestry, (6), 102-108.

Lo PICcolo, F., \& Todaro, V. (2013):La continuidad ecológicoambiental como estrategia de ordenación del territorio. Ciudad Y Territorio Estudios Territoriales (СуTET), 45(178), 789-797. https://recyt.fecyt. es/index.php/CyTET/article/view/76273

Losada, I.; Izaguirre, C. \& Diaz, P. (2014): Cambio climático en la costa española, Madrid, España, Oficina Española de Cambio Climático, Ministerio de Agricultura, Alimentación y Medio Ambiente.

MELL, I.C. (2008): Green Infrastructure: concepts and planning. FORUM Ejournal, Vol. 8 (June 2008), 69-80.

Padilla, A. \& al. (2019): El papel del inventario ambiental exhaustivo en el proceso de la configuración 
definitiva de la Infraestructura Verde del litoral sur de la Comunitat Valenciana. Boletín de la Asociación de Geógrafos Españoles, Vol. 82, 2805, 1-37.

PuJADAs, R. \& Font, J. (1998): Ordenación y planificación territorial, Madrid, Síntesis.

Rando, E. (2019): "Tres cuestiones jurídicas de actualidad en las políticas territoriales cántabras". En FUNDICOT, $9^{\circ}$ Congreso Internacional de Ordenación del Territorio: Planificación y gestión integrada como respuesta (pp. 81-97), Madrid, España, FUNDICOT.

URIARTE, M. (2014): Planificar la infraestructura verde urbana. Revista Vasca de Administración Pública. Herri-Arduralaritzako Euskal Aldizkaria (99-100), 2.873-2.895

Valladares, F., Gil, P. \& Forner, A. (coord.) (2017): Bases científicotécnicas para la Estrategia estatal de infraestructura verde $y$ de la conectividad $y$ restauración ecológicas, Madrid, España, Ministerio de Agricultura y Pesca, Alimentación y Medio Ambiente.

VeGA, J.J. \& al (2019): "Una propuesta para la integración de la infraestructura verde en el modelo territorial de Cantabria". En FUNDICOT, $9^{\circ}$ Congreso Internacional de Ordenación del Territorio: Planificación y gestión integrada como respuesta (p. 497), Madrid, España, FUNDICOT.

Vera-Rebollo, J.F. \& Olcina, J. (2017): Análisis de la coherencia metodológica y de los datos utilizados en la memoria justificativa del PATIVEL. [inédito] Conselleria de Vivienda, Obras Públicas y Vertebración del Territorio de la Generalitat Valenciana, Universidad de Alicante.

Vera-Rebollo, J.F.; Olcina, J. \& Sainz-Pardo, A. (2019): La incorporación de la infraestructura verde en la ordenación territorial. El plan de acción territorial de la infraestructura verde del litoral de la Comunidad Valenciana, PATIVEL. Ciudad y
Territorio. Estudios Territoriales, Vol. LI (200), 467-490.

Weber T.; Sloan, A. \& Wolf, J. (2006) Maryland's Green Infrastructure assessment: development of a comprehensive approach to land conservation". Landscape and Urban Planning, Vol. 77 (1-2), 94-110.

\section{Listado de acrónimos/siglas}

\section{AEMA Agencia Europea del Medio Ambiente \\ CAPV Comunidad Autónoma del País Vasco \\ CE Comisión Europea \\ DOT Directrices de Ordenación Territorial}

ESPON Observatorio en Red de la Ordenación del Territorio Europeo

ETCV Estrategia Territorial de la Comunitat Valenciana

GRETA Green infrastructure: Enhancing biodiversity and ecosystem services for territorial development

PAT Plan de Acción Territorial

PATIVEL Plan de Acción Territorial de Infraestructura Verde del Litoral

POL Plan de Ordenación del Litoral

PROT Plan Regional de Ordenación Territorial

PTP Planes Territoriales Parciales 